Article

\title{
First Description of a Temperate Bacteriophage (vB_FhiM_KIRK) of Francisella hispaniensis Strain 3523
}

\author{
Kristin Köppen ${ }^{1,+}$, Grisna I. Prensa ${ }^{1,+}$, Kerstin Rydzewski ${ }^{1}$, Hana Tlapák ${ }^{1}$, Gudrun Holland ${ }^{2}$ \\ and Klaus Heuner ${ }^{1, *}$ \\ 1 Centre for Biological Threats and Special Pathogens, Cellular Interactions of Bacterial Pathogens, ZBS 2, \\ Robert Koch Institute, 13353 Berlin, Germany; koeppenk@rki.de (K.K.); prensag@rki.de (G.I.P.); \\ rydzewskik@rki.de (K.R.); hana.tlapak@julius-kuehn.de (H.T.) \\ 2 Centre for Biological Threats and Special Pathogens, Advanced Light and Electron Microscopy, ZBS 4, \\ Robert Koch Institute, D-13353 Berlin, Germany; hollandg@rki.de \\ * Correspondence: heunerk@rki.de; Tel.: +49-30-18754-2226 \\ + Both authors contributed equally to this work.
}

\section{check for} updates

Citation: Köppen, K.; Prensa, G.I.; Rydzewski, K.; Tlapák, H.; Holland, G.; Heuner, K. First Description of a Temperate Bacteriophage (vB_FhiM_KIRK) of Francisella hispaniensis Strain 3523. Viruses 2021, 13, 327. https://doi.org/10.3390/ v13020327

Academic Editors: Tessa E. F. Quax, Marianne De Paepe and Karin Holmfeldt

Received: 3 February 2021

Accepted: 18 February 2021

Published: 20 February 2021

Publisher's Note: MDPI stays neutral with regard to jurisdictional claims in published maps and institutional affiliations.

Copyright: (c) 2021 by the authors. Licensee MDPI, Basel, Switzerland. This article is an open access article distributed under the terms and conditions of the Creative Commons Attribution (CC BY) license (https:// creativecommons.org/licenses/by/ $4.0 /)$.

\begin{abstract}
Here we present the characterization of a Francisella bacteriophage (vB_FhiM_KIRK) including the morphology, the genome sequence and the induction of the prophage. The prophage sequence (FhaGI-1) has previously been identified in F. hispaniensis strain 3523. UV radiation induced the prophage to assemble phage particles consisting of an icosahedral head ( $\sim 52 \mathrm{~nm}$ in diameter), a tail of up to $97 \mathrm{~nm}$ in length and a mean width of $9 \mathrm{~nm}$. The double stranded genome of vB_FhiM_KIRK contains 51 open reading frames and is $34,259 \mathrm{bp}$ in length. The genotypic and phylogenetic analysis indicated that this phage seems to belong to the Myoviridae family of bacteriophages. Under the conditions tested here, host cell (Francisella hispaniensis 3523) lysis activity of KIRK was very low, and the phage particles seem to be defective for infecting new bacterial cells. Nevertheless, recombinant KIRK DNA was able to integrate site-specifically into the genome of different Francisella species after DNA transformation.
\end{abstract}

Keywords: Francisella hispaniensis; FhaGI-1; prophage; KIRK; bacteriophage; Myoviridae; vB_FhiM_KIRK

\section{Introduction}

Francisella tularensis is a Gram-negative zoonotic bacterium able to cause tularemia in a wide range of animals and in humans, where it causes various clinical expressions ranging from skin lesions to severe pneumonia, depending on the route of infection [1,2]. Infections in humans are mostly associated with the highly virulent F. tularensis subsp. tularensis (Ftt) and the less virulent subsp. F. tularensis subsp. holarctica (Fth) [3]. In individuals with compromised immune system opportunistic infections by other Francisella species, such as F. novicida (Fno), F. hispaniensis (Fhi) and F. philomiragia (Fph), have been reported [4-6]. Fno is an environmental, water-associated, less pathogenic species $[4,5]$.

Fhi strain 3523 was isolated from a patient infected by this bacterium as a result of a cut received in brackish water in North Territory of Australia and was initially believed to be a Fno-like species [6]. It was the first reported Francisella strain from the Southern hemisphere. This strain was later re-classified to Fhi [6,7], a new species described in 2010 with Fhi type strain FhSp1 (= FSC454 = DSM 22475 = CCUG 58020), isolated from a patient in Spain [8], as the reference strain [9]. The whole genome of Fhi 3523 was sequenced in 2011 (Accession number CP002558) and the authors mentioned a putative prophage region together with a gene cluster coding for a putative RtxA toxin [10]. The putative prophage is not present in the genome sequence of the Fhi strain FSC454.

In 2013 we analyzed various Francisella genomes for the presence of putative functional CRISPR-Cas systems (clustered regularly interspaced short palindromic repeats/CRISPRassociated) and identified such systems in different Fno and Fno-like strains, including 
Fhi 3523 [11]. CRISPR-Cas systems are RNA-guided adaptive immunity-like systems to protect bacteria against foreign DNA, like plasmids and bacteriophages [12-17]. Parts of the foreign DNA are integrated as so called "spacer DNA" into the CRISPR system. This DNA is then used to degrade (silence) foreign DNA in a sequence-specific manner. The DNA of the CRISPR system thus represents foreign DNA which the bacterial strain has been encountered with. Analyzing the spacer sequences of the CRISPR region of various Francisella strains, we identified DNA sequences found entirely in the same region of the genome of Fhi 3523 (see Figure 1A, red arrows). We identified this region to represent a genomic island (FhaGI-1), able to generate an extrachromosomal (episomal) circular form, encoding a putative prophage [11,18]. Generation of this episomal form depend on the presence of a site-specific integrase/recombinase $[11,18]$. The repeat region $(a t t P)$ and the integrase (int) of FhaGI-1 were then used to generate a new Francisella integration vector (pFIV-Val) which integrates site-specifically into the tRNA-Val gene of different Francisella species [19].
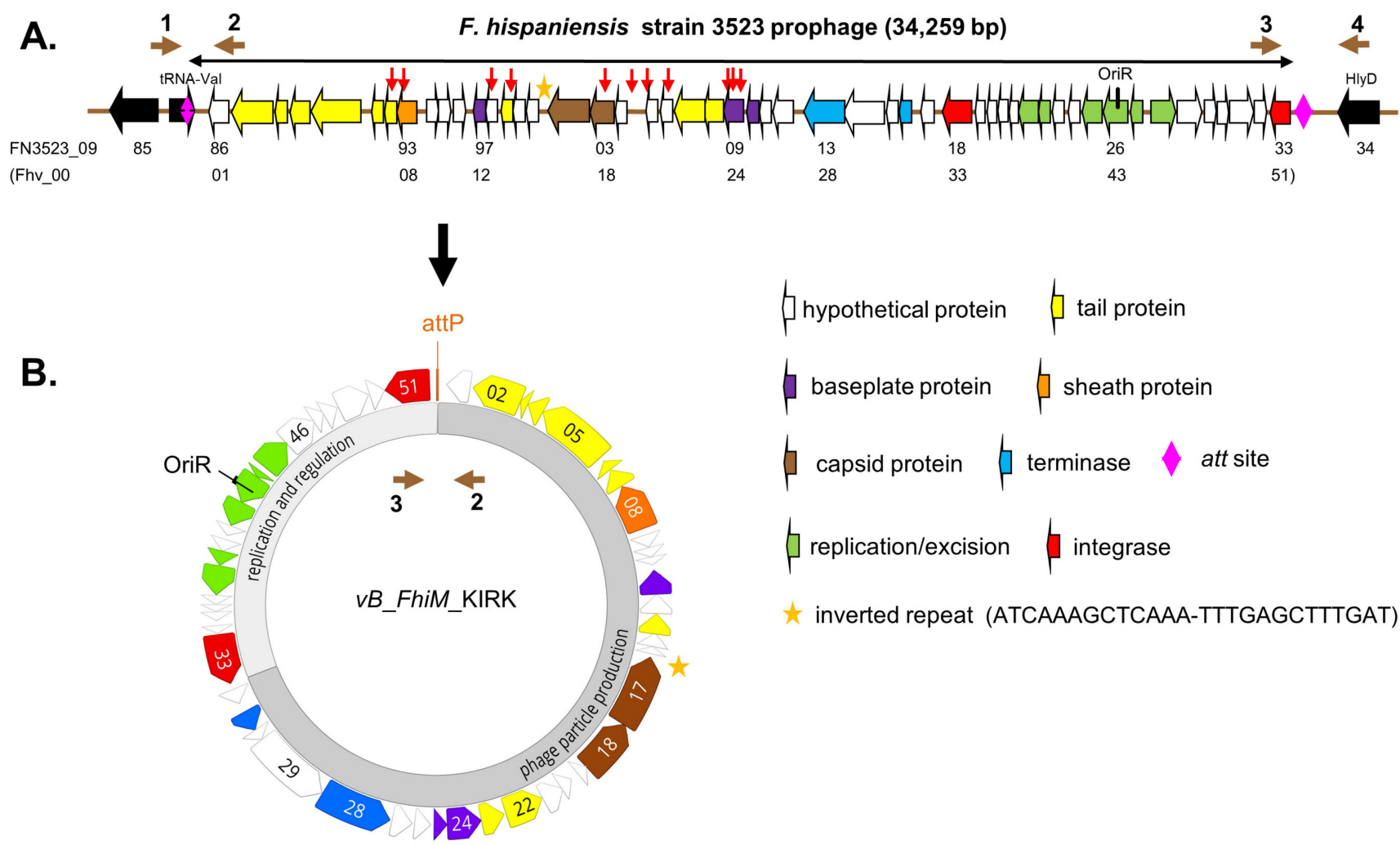

Figure 1. Organization of Francisella bacteriophage vB_FhiM_KIRK as prophage (A) or its episomal form (B). (A): The prophage is integrated within the tRNA-Val gene (pink arrow). The att sites (attL and attR) are indicated by a pink trapezium. The attR site corresponds to the $3^{\prime}$ end of the tRNA-Val. Chromosomal genes are given in black and genes of the bacteriophage are given in different colours according to their respective putative function based on BLASTp analysis (see also Table 1). A putative origin of replication (OriR) is indicated. Gene numbers are indicated below the genes as published for Fhi 3523 (FN3523; CP002558) or as determined in this work for the bacteriophage KIRK (FhV_0001 to FhV_0051). Location of the spacer DNAs identified in the CRISPR-Cas systems of different Francisella strains are indicated above of the genes by red arrows (Schunder et al., 2013; modified). Primer used in this study are indicated as brown arrows (for details see text). (B): Gene organization of the episomal form of bacteriophage KIRK are given in different colours (see (A)) due to their putative function and are clustered in "replication and regulation" and "phage particle production". The site-specific DNA region of KIRK (attP) responsible for the integration into the genome of host cells (attB, not shown) is indicated.

Prophages (integrated bacterial virus genomes) are commonly found in many bacterial genomes, encoding viruses/phages that can infect bacteria (bacteriophages). dsDNA 
phages can be divided in two groups: lytic and temperate (lysogenic). Lytic dsDNA phages infect bacterial cells. After replication and synthesis of new virion particles, phages are released by lysing and consequently killing their host cells. Temperate dsDNA phages are able to stably integrate into the genome of host bacteria, often at specific integration sites. However, prophages can be induced either by different environmental factors (stress conditions, temperature, UV-light, radiation) or spontaneously switch to the lytic pathway. While a lot of these prophages appear to be defective, many genes of such prophages remain functional. Thus, phage particles are produced, but the produced bacteriophages are non-functional [20]. In addition, phages are likely to serve as important vehicles for horizontal gene transfer between bacteria [21,22].

There was a preliminary communication in 1959 about lytic material derived from a culture of F. tularensis, yet, without describing bacteriophages [23]. In 2007, first evidence of Legionella bacteriophages in environmental water samples was published. One year later, another group demonstrated that bacteriophages isolated from organs of guinea pigs infected with Philadelphia 1 strain of $L$. pneumophila exhibit a certain lytic activity against $F$. tularensis [24,25]. In addition, in a PhD work in 2014 phage-like particles were described which seem to be able to infect Francisella cells, but neither the putative prophage genome nor the phage genome was determined and to our knowledge the data were yet not further published [26]. Considering that less is known about horizontal gene transfer in Francisella, and that no phage has been characterized in Francisella species yet [10,23,25,27-29], we were interested to further analyze the putative temperate bacteriophage encoded by FhaGI-1.

In this work, we could demonstrate that the prophage (FhaGI-1) of Fhi 3523 encodes a bacteriophage (vB_FhiM_KIRK) that can be induced by UV-radiation.

\section{Materials and Methods}

\subsection{Strains, Media and Growth Conditions}

Strains used in this study were Fhi strain 3523 (= Fno-like clinical isolate 3523=Fhi AS02-814 [CDC accession number]; kindly provided by Jeannine Petersen, CDC) [6], Francisella sp. strain W12-1067 (F-W12); [30], Fth LVS (ATCC 29684), Fno strain U112 (ATCC 15482) and Fno strain Fx1 (FSC156, [4], Fph 25015 (ATCC 25015), Fhi (DSM 22475); Legionella pneumophila strain Corby [31] and Paris (CIP 107629), L. micdadei (ATCC 33218), L. dumoffii (ATCC 33279, L. bozemanii (ATCC 33217), L. oakridgensis (ATCC 33761), and Escherichia coli (DH10B) One Shot ${ }^{\circledR}$ TOP 10 (Invitrogen, Karlsruhe, Germany).

Francisella strains were cultivated at $37^{\circ} \mathrm{C}$ in medium T (MT) $(1 \%$ brain heart infusion broth (Difco Laboratories, Inc., Sparks, MD, USA), 1\% bacto tryptone (Difco Laboratories, Inc., Sparks, MD, USA), $1 \%$ technical casamino acids (Difco Laboratories, Inc., Sparks, MD, USA), $0.005 \%$ of $\mathrm{MgSO}_{4}, 0.01 \% \mathrm{FeSO}_{4}, 0.12 \%$ sodium citrate, $0.02 \% \mathrm{KCl}, 0.04 \% \mathrm{~K}_{2} \mathrm{HPO}_{4}$, $0.06 \%$ L-cysteine and $1.5 \%$ glucose) [32,33] or on MT agar plates supplemented with hemoglobin and charcoal (MTKH plates, [19]). E. coli strains were grown at $37^{\circ} \mathrm{C}$ in lysogeny broth (LB; $1 \%$ bacto tryptone, $0.5 \%$ yeast extract, $0.5 \% \mathrm{NaCl}$ ) or on $\mathrm{LB}$ agar (LB supplemented with $1.2 \%$ agar). Legionella strains were cultivated at $37^{\circ} \mathrm{C}$ in YEB (YeastExtract-Broth, $1 \% \mathrm{~N}$-(2-acetamido)-2-aminoethanesulfonic acid (ACES), 1\% yeast extract, $0.04 \%$ L-cysteine, $0.025 \%$ ferric pyrophosphate) medium or on ACES-buffered charcoalyeast extract (BCYE) agar (YEB supplemented with 1.5\% agar) [34]. Kanamycin was used at a concentration of $12 \mu \mathrm{g} \mathrm{mL}^{-1}$ for Francisella and $40 \mu \mathrm{g} \mathrm{mL}^{-1}$ for E. coli; chloramphenicol was used at a concentration of $10 \mu \mathrm{g} \mathrm{mL}^{-1}$ for Francisella and $40 \mu \mathrm{g} \mathrm{mL}-1$ for E. coli.

Growth of bacteria (culture density) was monitored with Cell Growth Quantifier (CGQ, Aquila BioLabs, Baesweiler, Germany) at $37^{\circ} \mathrm{C}$ and $250 \mathrm{rpm}$.

\subsection{DNA Techniques and PCR Analysis}

Plasmid DNA was prepared using the Invisorb Plasmid Mini Two Kit (Stratec, Berlin, Germany), the episomal form of the prophage was extracted using the GeneJET PlasmidMidiprep-Kit (ThermoFisher, Waltham, MA, USA), and preparation of total DNA was done using the Blood \& Tissue kit (Qiagen, Hilden, Germany) and used as control DNA 
in PCR experiments. The whole DNA preparation of Fhi 3523 has been shown to contain the episomal form of the prophage at least in a small amount [18]. Restriction enzymes were purchased from New England BioLabs (Frankfurt a. M., Germany) and were used according to the manufacturer's protocols.

The cloning strategy to generate a recombinant phage $\mathrm{KIRK}_{\text {rec }}$ is outlined in Supplemental Materials. Briefly, the whole bacteriophage was in vitro synthesized as two fragments (5'-region [GI-1 plus GFP and a second att-site] and $3^{\prime}$-region [GI-2 plus a kanamycin resistance gene]) of the prophage (GeneCust, Boynes, France). Both constructs were electroporated into strain F-W12 and integrated into the genome by the integrase of the bacteriophage (Supplemental Figure S1).

PCR was carried out using a Thermocycler TRIO-Thermoblock (Biometra, Göttingen, Germany) and the TopTaq DNA polymerase (Qiagen, Hilden, Germany) according to manufacturer instructions. Primers used in this study are listed in Supplemental Materials Table S1 and are indicated in Figure 1A. In strain Fhi 3523 the chromosomal tRNA-Val region was amplified with primer Fha-1/Fha-4. The amplification of the circular form of FhaGI-1 (episomal/extrachromosomal) was done with primer Fha-2/Fha-3, even though this primer combination might also amplify the linear phage DNA which is generated towards the end of the lytic cycle when concatemers (multiple copies of phage DNA) are formed, cut and packed into proheads. attP sites (facilitating integration into host genome of the circular prophage) and linear phage DNA termini (e.g., cos and pac, depending on the DNA packing process) are usually not identical. Chromosomal integration of the bacteriophage was shown by the primer combinations Fha-1/Fha-2 and Fha-3/Fha- 4 . In general, initial denaturation was performed at $94{ }^{\circ} \mathrm{C}$ for $3 \mathrm{~min}$, and final extension was performed at $72{ }^{\circ} \mathrm{C}$ for $10 \mathrm{~min}$. Cycling conditions comprised 35 cycles at $94{ }^{\circ} \mathrm{C}$ for $30 \mathrm{~s}, 57^{\circ} \mathrm{C}$ for $1 \mathrm{~min}$ and $72{ }^{\circ} \mathrm{C}$ for $1 \mathrm{~min}$, and $100 \mathrm{ng}$ of template DNA was used. Oligonucleotides were ordered from Eurofins MWG Operon (Ebersberg, Germany).

\subsection{Transformation of Bacteria}

Plasmid DNA was introduced into E. coli by thermal shock (30 min on ice, $30 \mathrm{~s}$ at $42{ }^{\circ} \mathrm{C}, 2$ min on ice). After transformation E. coli were incubated in LB medium at $37{ }^{\circ} \mathrm{C}$ for $1 \mathrm{~h}$ and then plated onto selective agar. For the generation of electrocompetent Francisella, bacteria were grown in medium T overnight, pelleted (4500 g for $15 \mathrm{~min}$ ) and washed twice in $0.5 \mathrm{M}$ sucrose. Electroporation was performed at $2.5 \mathrm{kV}, 600 \Omega$ and $25 \mu \mathrm{F}$ using a Gene Pulser system (Bio-Rad, Munich, Germany). After transformation Francisella were incubated in medium $\mathrm{T}$ for $4 \mathrm{~h}$ at $37^{\circ} \mathrm{C}$ and then plated onto selective MTKH agar plates.

\subsection{Phage Induction Experiments}

Temperature stress. An overnight culture of Fhi 3523 was diluted with medium T to $\mathrm{OD}_{600}=1 \mathrm{~mL}$ and $7 \mathrm{~mL}$ aliquots were incubated at $37{ }^{\circ} \mathrm{C}, 42{ }^{\circ} \mathrm{C}$ or $44{ }^{\circ} \mathrm{C}$ up to $24 \mathrm{~h}$. Samples were collected after 1, 3, 5, 7 and 24 h of incubation and used for PCR analysis, as described below.

Mitomycin C stress. An overnight culture of Fhi 3523 was diluted with medium T to $\mathrm{OD}_{600}=1 \mathrm{~mL}$ and $7 \mathrm{~mL}$ aliquots were exposed to different concentrations $(0 \mu \mathrm{g} / \mathrm{mL}$, $0.5 \mu \mathrm{g} / \mathrm{mL}, 1.0 \mu \mathrm{g} / \mathrm{mL}$ and $5.0 \mu \mathrm{g} / \mathrm{mL}$ ) of Mitomycin C (MMC) for up to $24 \mathrm{~h}$. Samples incubated without MMC were used as a control for spontaneous induction of the prophage.

UV stress. Using this method, DNA of Fhi 3523 liquid cultures were damaged by UV radiation according to the methods described by Woods [35]. An overnight culture was adjusted to $\mathrm{OD}_{600}=1 \mathrm{~mL}$ and $15 \mathrm{~mL}$ were centrifuged at $4500 \times \mathrm{g}$ for $15 \mathrm{~min}$. The pellet resuspended in $\frac{1}{2}$ volumes $0.01 \mathrm{M} \mathrm{MgSO}_{4}$ and $3 \mathrm{~mL}$ were transferred to a small petri dish. An UV hand lamp was positioned $50 \mathrm{~cm}$ above the petri dish to radiate a wavelength of $254 \mathrm{~nm}$ for different time intervals $(0,30,60$ and $90 \mathrm{~s})$. After radiation the entire volume was transferred to $12 \mathrm{~mL}$ medium $\mathrm{T}$ and incubated at $37^{\circ} \mathrm{C}$ and $250 \mathrm{rpm}$ for up to $24 \mathrm{~h}$. After 2, 3, 4, 5, 6, 7 and $24 \mathrm{~h}$ of incubation samples were taken and used for further analysis (see below). 
Collected samples of treated Fhi 3523 cultures (temperature, MMC, UV; see above) were adjusted to $\mathrm{OD}=1$, and $50 \mu \mathrm{L}$ aliquots were centrifuged $(5000 \times g, 5 \mathrm{~min})$. Supernatants were discarded and pellet resuspended in $50 \mu \mathrm{L} \mathrm{H} \mathrm{H}_{2} \mathrm{O}$. After heat treatment $\left(100{ }^{\circ} \mathrm{C}\right.$ for $10 \mathrm{~min}$ ) samples were pelleted (5000 $\mathrm{g}, 5 \mathrm{~min}$ ) and $15 \mu \mathrm{L}$ of supernatants were used as DNA template for PCR analysis using primer Fha-2/Fha-3 with 10 amplification cycles.

\subsection{Cell Disruption and Phage Purification}

Cell disruption. To be able to isolate phage particles from UV-induced bacterial cells (see Section 2.4), independent of phage mediated lysis, cells were disrupted by sonication. After UV-radiation, bacteria were incubated at $37^{\circ} \mathrm{C}$ for $5-6 \mathrm{~h}$ at $250 \mathrm{rpm}$ and centrifuged for $15 \mathrm{~min}$ at $4500 \times \mathrm{g}$. The bacterial pellet was resuspended in $2 \mathrm{~mL}$ PBS and cooled down on ice. Afterwards the sample was sonicated on ice using a sonicator by Bandelin with an ultrasonic pulse period of $5 \times 30 \mathrm{~s}, 60 \%$ amplitude and $70 \%$ pulse operation. The samples were used for EM analysis (Section 2.6).

Phage purification. To isolate phages from UV-induced Fhi 3523, bacteria were cultivated after UV induction (see Section 2.4) for $6 \mathrm{~h}$ and pelleted at $4500 \mathrm{~g}$ for $15 \mathrm{~min}$. After transferring the supernatant to a new Falcon tube, DNase and RNase were added (final concentration of $1 \mu \mathrm{g} / \mathrm{mL}$ each) and incubated at $37^{\circ} \mathrm{C}$ for $30 \mathrm{~min}$, followed by sterile filtration (0.22 $\mu \mathrm{m}$ pores (Millipore, Merck, Darmstadt, Germany). Purified (not concentrated) phage samples were used for PCR analysis, EM analysis, spot tests and infection experiments (Section 2.7).

\subsection{Electron Microscopy (EM)}

Bacterial lysates and purified phages (see Section 2.5) were diluted with distilled water (1:10) and sedimented (5000 g, $10 \mathrm{~min}$.). The resulting supernatant was adsorbed to pioloform filmed, alcian blue treated copper grids, washed five times with distilled water and stained with uranyl acetate $(0.5 \%$ in distilled water) for $10 \mathrm{~s}$.

To visualize the assembly of new phages within the bacterial cells thin section EM was performed. UV induced liquid cultures of bacteria were sedimented at $4500 \mathrm{~g}$ for $15 \mathrm{~min}$, and pellet was resuspended in $5 \mathrm{~mL}$ fixative $(2.5 \%$ glutaraldehyde $+1 \%$ formaldehyde in 0.05 M HEPES buffer). After incubation in fixative at room temperature for $2 \mathrm{~h}$, with occasional inverting of the vials for optimal penetration of the fixative into the cells, bacteria were embedded in low-melting point agarose (3\% in distilled water). Small blocks of agarose-embedded bacteria were post-fixed with osmium tetroxide ( $1 \%$ in distilled water) and uranyl acetate ( $2 \%$ in distilled water), dehydrated stepwise in a graded ethanol series and embedded in LR White resin (Science Services GmbH, Munich, Germany) which was polymerized at $60{ }^{\circ} \mathrm{C}$ overnight. Thin sections were prepared with an ultramicrotome (UC-T; Leica, Wetzlar, Germany) and counterstained with uranyl acetate and lead citrate.

Samples were examined using a transmission electron microscope (Tecnai Spirit, Thermo Fischer/FEI, Hennigsdorf, Germany) operated at $120 \mathrm{kV}$. Images were recorded using a charge-coupled-device camera (Megaview III, OSIS, Klosterneuburg, Austria) at a resolution of $1376 \times 1032$ pixel.

\subsection{Phage Plate (Spot) Test and Phage Infection Assays}

For the determination of the lysis spectrum of purified phages the soft-agar overlay technique (spot test) was used as described by Hockett and colleagues [36]. Briefly, different Francisella (Fhi, Fth, Fph, F-W12) and Legionella (L. pneumophila, L. micdadei, L. oakridgensis, L. bozemanii, L. dumoffii) species were tested as hosts. Therefore, $100 \mu \mathrm{L}$ of exponentially grown bacteria were transferred to $4 \mathrm{~mL}$ of $50-60{ }^{\circ} \mathrm{C}$ heated $0.5 \%(w / v)$ soft-agar, gently mixed and poured over a MTKH (Francisella sp.) or BCYE (Legionella sp.) agar plate. After $30 \mathrm{~min}$ of curing, $10 \mu \mathrm{L}$ aliquots of purified phage samples (see Section 2.5) were pipetted on the soft-agar, left to dry and incubated at $37^{\circ} \mathrm{C}$ until a bacterial lawn became visible. The plates were then checked for lysed zones. As a negative control, aliquots of medium T-MgSO 4 suspension and supernatants of Francisella strains lacking KIRK were used. 
Phage infection assays using kanamycin gene tagged KIRK (KIRK $\left.\mathrm{K}_{\text {rec }}\right)$. To further investigate the ability of KIRK to infect bacteria, we used the kanamycin resistant KIRK $_{\text {rec }}$ phage. To isolate $\mathrm{KIRK}_{\text {rec }}$, bacterial strains containing the recombinant phages were induced by UV radiation to isolate the recombinant phage particles as described above (see Sections 2.4 and 2.5). Respective bacterial strains $(800 \mu \mathrm{L}$ ) were mixed with $200 \mu \mathrm{L}$ of $\mathrm{KIRK}_{\text {rec }}$ containing crude phages and incubated at $37^{\circ} \mathrm{C}$ for $2 \mathrm{~h}$. Different dilutions were plated onto Km-containing MTKH (Francisella sp.) or BCYE (Legionella sp.) agar plates. In addition, several subcultivation were done in medium $\mathrm{T}$ supplemented with $\mathrm{Km}$ after infection. $\mathrm{Km}$ resistant clones and bacterial cell pellets were analyzed for the presence of episomal and/or integrated forms of recombinant KIRK by PCR (primers Fha-2/Fha-3; Fha-1/Fha-2; Fha-3/Fha-4).

\subsection{Phylogenetic Analysis}

Multi protein sequences (in frame amino acid sequence) of genes fhv_0008, 0012, 0018, 0023, 0024, 0025 and fhv_0028 of KIRK and available homologous proteins from phages (Myoviridae): Escherichia T4 (Tevenvirinae, AF158101), Escherichia 186 (Peduovirinae, NC_001317), Escherichia P2 (Peduovirinae, KC618326), Vibrio VHML (Vhmlvirus, NC_004456), Vibrio VP585 (Vhmlvirus, NC_027981), Wolbachia WO2 (MK976036), Wolbachia WO (MN180249), Ralstonia phiRSP (Jilinvirus, MH252365), Pseudomonas PPpW3 (Jilinvirus, NC_023006), Enterobacter Arya (Jilinvirus, NC_031048), Escherichia ECO-1230-10 (Jilinvirus, GU903191) and Escherichia EcoM-ep3 (Jilinvirus, NC_025430) (obtained from GenBank) were used for amino acid sequences alignment, using the ClustalO program in Geneious. Phylogenetic analysis (phylogenetic tree) was performed by using Geneious Prime (Geneious Tree Builder, Neighbor-Joining method, Escherichia T4 phage as outgroup).

\section{Results}

\subsection{Genetic Organization and Open Reading Frames (ORFs)}

We identified a genomic island (FhaGI-1) within the genome of Fhi strain 3523 encoding a putative prophage $[11,18]$ (Figure 1A). The putative prophage DNA sequence starts with the attL site, which is a part of the bacterial tRNA-Val gene and is located upstream of protein Fhv_0001 (= FN3523_0986 of the prophage). It ends with a site-specific integrase (int; Fhv_0051; FN3523_1033) located upstream of the attR site, which represents the $3^{\prime}$ end of the chromosomal tRNA-Val gene (Figure 1A). In this study, we re-analyzed the prophage DNA sequence exhibiting a length of $34,259 \mathrm{bp}$ and a GC content of $33.8 \%$ (Figure 1B). We identified three additional open reading frames (ORFs Fhv_0036/37/48)-compared to the annotated and published ORFs of Fhi $3523[10,11]$, revealing now 51 putative proteins (Figure 1). The putative Francisella bacteriophage was named KIRK.

In Figure 1B the overview of the circular genome sequence of KIRK is shown, containing a regulatory and a phage particle production region. The regulatory region encodes the putative regulatory proteins Cro (phage CI repressor, Fhv_0044), a CI-type protein (Pro-phage repressor, Fhv_0045) exhibiting a LexA domain and a putative CII replication protein (Fhv_0043); containing an amino acid repeat (KDNNK, 3 times). Furthermore, a putative origin of replication composed of an OriR sequence (inceptor signal for DNA replication), is found upstream of four repeating units (iterons, misc-binding sites) localized within an AT-rich region [37] (see Figure 2). The sequence possesses a putative helicase (Fhv_0042) and a putative anti-repressor protein (Fhv_0038). 


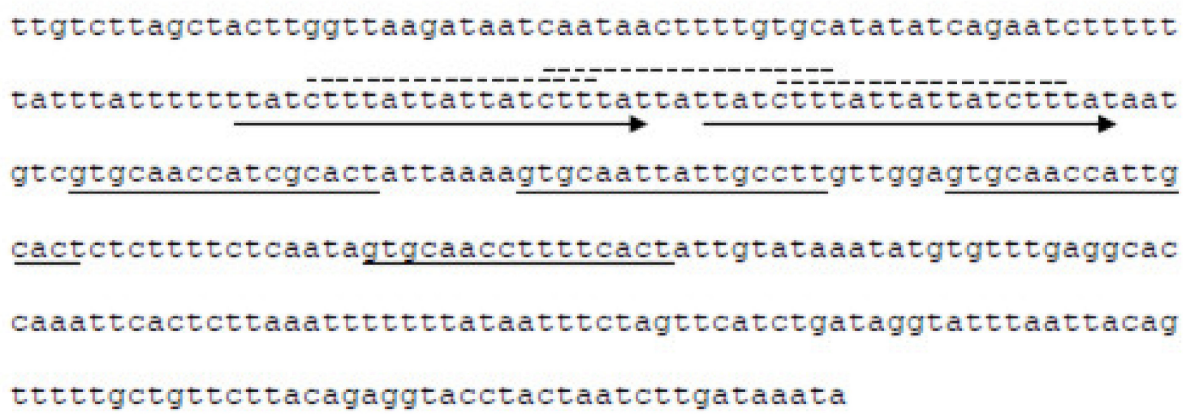

Figure 2. The putative origin of replication of vB_FhiM_KIRK. The origin is composed of the putative inceptor signal for DNA replication (dotted lines, three times), found within a direct repeat sequence (arrows), and four misc-binding sites (underlined sequence). The region is localized within gene fho_0043 (see Figure 1).

Table 1. Putative proteins encoded by ORFs Fhv_0001 to Fhv_0051 of KIRK.

\begin{tabular}{|c|c|c|c|c|c|}
\hline ORF Number & Aa & Motif/Putative Function & $\begin{array}{l}\text { putative Function in } \\
\text { Phages According to } \\
\text { HHpred \# (Probability) }\end{array}$ & $\begin{array}{l}\text { BLASTp Viruses } \\
\text { (Identity) }\end{array}$ & $\begin{array}{l}\text { BLASTp Francisella } \\
\text { Group (Identity }{ }^{*} \text { ) }\end{array}$ \\
\hline Fhv_0001 (0986) ${ }^{* *}$ & 197 & $2 \times$ internal repeat, $\mathrm{HP}$ & Major capsid protein (50\%) & $\begin{array}{l}\text { Aedes pseudoscutellaris } \\
\text { reovirus VP6 }(25 \%)\end{array}$ & - \\
\hline Fhv_0002 (0987) & 408 & $\begin{array}{l}\text { Phage_GPD, } \\
\text { GpD phage late control } \\
\text { protein D }\end{array}$ & Tail protein $(100 \%)^{\circ}$ & $\begin{array}{l}\text { Wolbachia phage WO } \\
\qquad(30 \%)^{\circ}\end{array}$ & $\begin{array}{l}\text { Francisella sp. SYW-9 } \\
\qquad(47 \%)\end{array}$ \\
\hline Fhv_0003 (0988) & 066 & $\begin{array}{c}\text { Phage_tail_X } \\
\text { Phage tail protein }\end{array}$ & - & $\begin{array}{l}\text { Wolbachia phage WO } \\
\qquad(55 \%)\end{array}$ & $\begin{array}{l}\text { Francisella sp. SYW-9 } \\
(55 \%)\end{array}$ \\
\hline Fhv_0004 (0989) & 138 & $\begin{array}{c}\text { Phage_P2_GpU } \\
\text { Phage tail assembly }\end{array}$ & $\begin{array}{l}\text { Major tube protein gp53 } \\
(86 \%)\end{array}$ & Caudovirales phage $(29 \%)^{\circ}$ & $\begin{array}{l}\text { Francisella sp. SYW-9 } \\
(43 \%)\end{array}$ \\
\hline Fhv_0005 (0990) & 607 & $\begin{array}{l}\text { Coiled coil, } 3 \times \text { LCRs } \\
\text { Phage tail tape measure } \\
\text { protein }\end{array}$ & $\begin{array}{l}\text { Tape Measure Protein gp57 } \\
(99 \%)\end{array}$ & Vibrio phage VpKK5 (36\%) & $\begin{array}{c}\text { Francisella sp. SYW-9 } \\
(36 \%)\end{array}$ \\
\hline Fhv_0006 (0991) & 089 & $\begin{array}{c}\text { Phage_TAC_7 } \\
\text { Phage tail assembly } \\
\text { chaperone, Myoviridae }\end{array}$ & $\begin{array}{c}\text { Lambda integrase }(48 \%) \\
\text { DNA-binding protein gp33 } \\
(41 \%) \\
\text { Tail assembly chaperone } \\
(38 \%)\end{array}$ & $\begin{array}{l}\text { Pseudomonas phage PPpW-3 } \\
(31 \%)\end{array}$ & $\begin{array}{c}\text { Francisella sp. SYW-9 } \\
(53 \%)\end{array}$ \\
\hline Fhv_0007 (0992) & 159 & $\begin{array}{l}\text { Phage_tube } \\
\text { Major tail tube protein }\end{array}$ & $\begin{array}{l}\text { Tail tube protein gp19 } \\
\qquad(80 \%)^{\circ}\end{array}$ & $\begin{array}{l}\text { Wolbachia phage WO } \\
\qquad(35 \%)^{\circ}\end{array}$ & $\begin{array}{c}\text { Francisella sp. SYW-9 } \\
(51 \%)\end{array}$ \\
\hline Fhv_0008 (0993) & 385 & $\begin{array}{c}\text { Phae_sheath_1, } \\
\text { Phage_sheath_1C } \\
\text { Phage tail sheath protein }\end{array}$ & $\begin{array}{l}\text { Tail sheath protein Gp18 } \\
(100 \%)^{\circ}\end{array}$ & $\begin{array}{l}\text { Wolbachia phage WO } \\
\qquad(49 \%)^{\circ}\end{array}$ & $\begin{array}{c}\text { Francisella sp. SYW-9 } \\
(56 \%)\end{array}$ \\
\hline Fhv_0009 (0994) & 106 & $\mathrm{HP}$ & Integrase (21\%) & - & - \\
\hline Fhv_0010 (0995) & 081 & $\mathrm{HP}$ & Gene 9 protein Knob (23\%) & - & - \\
\hline Fhv_0011 (0996) & 066 & LCR, & arc repressor $(39 \%)$ & $\begin{array}{l}\text { Pseudomonas phage EL } \\
\qquad(50 \%)^{\circ}\end{array}$ & $\begin{array}{l}\text { F. tularensis subsp. } \\
\text { novicida PA10-7858 } \\
(50 \%)\end{array}$ \\
\hline Fhv_0012 (0997) & 198 & $\begin{array}{c}\text { Phage_base_V, } \\
\text { Baseplate assembly protein } \\
\mathrm{V}\end{array}$ & $\begin{array}{l}\text { Baseplate assembly protein } \\
\text { V }(100 \%)^{\circ}\end{array}$ & $\begin{array}{l}\text { Wolbachia phage WO } \\
\qquad(34 \%)^{\circ}\end{array}$ & $\begin{array}{c}\text { Francisella sp. SYW-9 } \\
(36 \%)\end{array}$ \\
\hline Fhv_0013 (0998) & 163 & $\mathrm{HP}$ & Minor tail protein U (97\%) & $\begin{array}{l}\text { Wolbachia phage WO } \\
\qquad(26 \%)^{\circ}\end{array}$ & - \\
\hline Fhv_0014 (0999) & 166 & $\begin{array}{l}166 \text { aa, LCR, minor tail_Z } \\
\text { superfamily } \\
\text { Phage minor tail protein }\end{array}$ & - & $\begin{array}{l}\text { Halomonas virus HAP1 } \\
(26 \%)^{\circ}\end{array}$ & $\begin{array}{c}\text { Francisella sp. SYW-9 } \\
(40 \%)\end{array}$ \\
\hline Fhv_0015 (1000) & 111 & $\mathrm{HP}$ & $\begin{array}{l}\text { Tail attachment protein } \\
\qquad(95 \%)\end{array}$ & - & $\begin{array}{c}\text { Francisella sp. SYW-9 } \\
(30 \%)\end{array}$ \\
\hline Fhv_0016 (1001) & 063 & $\mathrm{HP}$ & - & $\begin{array}{l}\text { Mediterranean phage } \\
\text { uvMED }(36 \%)\end{array}$ & - \\
\hline
\end{tabular}


Table 1. Cont.

\begin{tabular}{|c|c|c|c|c|c|}
\hline ORF Number & Aa & Motif/Putative Function & $\begin{array}{l}\text { putative Function in } \\
\text { Phages According to } \\
\text { HHpred \# (Probability) }\end{array}$ & $\begin{array}{l}\text { BLASTp Viruses } \\
\text { (Identity) }\end{array}$ & $\begin{array}{l}\text { BLASTp Francisella } \\
\text { Group (Identity }{ }^{*} \text { ) }\end{array}$ \\
\hline Fhv_0017 (1002) & 600 & $\begin{array}{c}\text { Peptidase_S78, } \\
\text { Phage_capsid } \\
\text { Major phage capsid protein }\end{array}$ & Major capsid protein $(100 \%)$ & $\begin{array}{c}\text { Escherichia phage } \\
\text { vB_EcoM_ECO1230-10 } \\
(37 \%)^{\circ}\end{array}$ & $\begin{array}{l}\text { Francisella sp. SYW-9 } \\
(40 \%)\end{array}$ \\
\hline Fhv_0018 (1003) & 473 & $\begin{array}{c}\text { Phage_portal_2, } \\
\text { portal_lambda } \\
\text { Phage hole protein, forming } \\
\text { DNA-ejection hole }\end{array}$ & Portal protein $(100 \%)$ & $\begin{array}{l}\text { Enterobacter phage Arya } \\
(34 \%)^{\circ}\end{array}$ & $\begin{array}{l}\text { Francisella sp. SYW-9 } \\
(39 \%)\end{array}$ \\
\hline Fhv_0019 (1004) & 088 & HP, coiled coil & $\begin{array}{l}\text { Head-to-tail joining protein } \\
\text { W }(89 \%)\end{array}$ & - & - \\
\hline Fhv_0020 (1005) & 110 & DUF1353, conserved HP & - & $\begin{array}{l}\text { Fusobacterium phage Funu2 } \\
(36 \%)^{\circ}\end{array}$ & F. marina $(46 \%)$ \\
\hline Fhv_0021 (1006) & 183 & HP, DUF4376 & $\begin{array}{l}\text { Tail fiber assembly protein } \\
\mathrm{U}(79 \%)^{\circ}\end{array}$ & - & - \\
\hline Fhv_0022 (1007) & 324 & $\begin{array}{l}\text { DUF3751, Pfam_12571 } \\
\text { Phage tail fibre protein }\end{array}$ & $\begin{array}{l}\text { Long-tail fiber proximal } \\
\text { subunit }(75 \%)^{\circ}\end{array}$ & $\begin{array}{c}\text { Salmonella phage } \\
\text { vB_SnwM_CGG4-1 }(35 \%)\end{array}$ & $\begin{array}{l}\text { Francisella sp. SYW-9 } \\
(42 \%)\end{array}$ \\
\hline Fhv_0023 (1008) & 195 & $\begin{array}{c}\text { Tail_P2_I, } \\
\text { Phage tail protein I }\end{array}$ & $\begin{array}{l}\text { Baseplate wedge protein } \\
\text { gp6 }(77 \%)\end{array}$ & $\begin{array}{l}\text { Ralstonia phage phiRSP } \\
(31 \%)^{\circ}\end{array}$ & $\begin{array}{c}\text { Francisella sp. SYW-9 } \\
(47 \%)\end{array}$ \\
\hline Fhv_0024 (1009) & 281 & $\begin{array}{l}\text { Baseplate_J, (P2 phage), gpJ } \\
\text { Phage-related baseplate } \\
\text { assembly protein }\end{array}$ & $\begin{array}{l}\text { Baseplate wedge protein } \\
\text { gp6 }(100 \%)^{\circ}\end{array}$ & $\begin{array}{l}\text { Pseudomonas phage PPpW-3 } \\
(36 \%)\end{array}$ & $\begin{array}{l}\text { Francisella sp. SYW-9 } \\
(52 \%)\end{array}$ \\
\hline Fhv_0025 (1010) & 112 & $\begin{array}{c}\text { GPW_gp25 T4 phage, } \\
\text { V1_zyme } \\
\text { Phage baseplate protein, } \\
\text { lysozyme activity }\end{array}$ & $\begin{array}{l}\text { Baseplate wedge protein } \\
\text { gp25 }(100 \%)^{\circ}\end{array}$ & $\begin{array}{l}\text { Ralstonia phage phiRSP } \\
\qquad(48 \%)^{\circ}\end{array}$ & $\begin{array}{l}\text { Francisella sp. SYW-9 } \\
\qquad(53 \%) \\
\text { F. philomiragia }(37 \%)\end{array}$ \\
\hline Fhv_0026 (1011) & 131 & HP, coiled coil, TM & Fibritin $(56 \%)^{\circ}$ & - & - \\
\hline Fhv_0027 (1012) & 169 & HP, LCR, TM & - & - & F. marina $(47 \%)$ \\
\hline Fhv_0028 (1013) & 602 & $\begin{array}{l}\text { Terminase_GpA, Phage } \\
\text { terminase large subunit, } \\
\text { DNA packaging }\end{array}$ & Terminase $(100 \%)$ & $\begin{array}{l}\text { Enterobacter phage Arya } \\
(48 \%)^{\circ}\end{array}$ & $\begin{array}{c}\text { Francisella sp. SYW-9 } \\
(59 \%)\end{array}$ \\
\hline Fhv_0029 (1014) & 671 & HP, 6x LCR & - & - & - \\
\hline Fhv_0030 (1015) & 093 & $\mathrm{HP}$ & - & - & F. marina $(40 \%)$ \\
\hline Fhv_0031 (1016) & 172 & $\begin{array}{c}\text { Phage_Nu1 SF } \\
\text { Minor subunit Nu1 of } \\
\text { terminase }\end{array}$ & $\begin{array}{l}\text { Regulatory protein cox } \\
\qquad(98 \%)^{\circ}\end{array}$ & $\begin{array}{l}\text { Mediterranean phage } \\
\text { uvMED }(29 \%)\end{array}$ & $\begin{array}{l}\text { F. philomiragia }(57 \%) \\
\text { F. novicida }(57 \%) \\
\text { F. salina }(57 \%)\end{array}$ \\
\hline Fhv_0032 (1017) & 128 & $\mathrm{HP}$ & $\begin{array}{l}\text { Middle operon regulator } \\
(100 \%)^{\circ}\end{array}$ & - & $\begin{array}{l}\text { Francisella novicida } \\
(33 \%)\end{array}$ \\
\hline Fhv_0033 (1018) & 422 & $\begin{array}{c}\text { Arm-DNA-bind_3, } \\
\text { Phage_Int_P4, } \\
\text { Phage integrase }\end{array}$ & Integrase $(100 \%)$ & $\begin{array}{l}\text { Pseudomonas phage } \\
\text { phiAH14b }(32 \%)\end{array}$ & $\begin{array}{c}\text { F. salina }(54 \%) \\
\text { F. novicida }(54 \%) \\
\text { F. philomiragia }(56 \%) \\
\text { Francisella sp. SYW-9 } \\
(48 \%)\end{array}$ \\
\hline Fhv_0034 (1019) & 106 & HP, LCR & - & - & - \\
\hline Fhv_0035 (1020) & 072 & $\mathrm{HP}$ & - & - & F. marina $(70 \%)$ \\
\hline $\begin{array}{l}\text { Fhv_0036 } \\
\text { (n.a.) }\end{array}$ & 061 & $\mathrm{HP}$ & - & $\begin{array}{c}\text { Megaviridae environmental } \\
\text { sample }(41 \%)\end{array}$ & $\begin{array}{l}\text { Francisella sp. } \\
\text { FSC1006 }(43 \%) \\
\text { F. marina }(45 \%)\end{array}$ \\
\hline $\begin{array}{l}\text { Fhv_0037 } \\
\text { (n.a.) }\end{array}$ & 075 & $\begin{array}{c}\text { HP, TM, conju_TIGR03752, } \\
\text { Integrating conjugative } \\
\text { element protein }\end{array}$ & $\begin{array}{c}\text { Fusion of phage phi29 Gp7 } \\
\text { protein and Cell division } \\
\text { protein FtsB }(64 \%)\end{array}$ & - & $\begin{array}{c}\text { Francisella sp. SYW-9 } \\
(50 \%)\end{array}$ \\
\hline Fhv_0038 (1021) & 240 & $\begin{array}{l}\text { Phage_pRha, ANT } \\
\text { Phage regulatory and } \\
\text { anti-repressor protein }\end{array}$ & Anti-sigma effector (45\%) & $\begin{array}{c}\text { Lactobacillus phage } \\
\text { phiEF-1.1 (66\%) }\end{array}$ & $\begin{array}{c}\text { Francisella sp. SYW-9 } \\
(54 \%) \\
\text { F. marina }(71 \%)\end{array}$ \\
\hline Fhv_0039 (1022) & 120 & $\begin{array}{c}\text { Phage_TIGR01671, YopX } \\
\text { Putative phage protein }\end{array}$ & $\begin{array}{c}\text { HP ORF041 (Staphylococcus } \\
\text { phage, } 100 \%)\end{array}$ & $\begin{array}{l}\text { Clostridium phage } \\
\text { phiCT19406C (41\%) }\end{array}$ & - \\
\hline Fhv_0040 (1023) & 100 & HP, coiled coil & $\begin{array}{l}\text { Long tail fiber distal } \\
\text { subunit }(24 \%)^{\circ}\end{array}$ & - & - \\
\hline
\end{tabular}


Table 1. Cont.

\begin{tabular}{|c|c|c|c|c|c|}
\hline ORF Number & Aa & Motif/Putative Function & $\begin{array}{l}\text { putative Function in } \\
\text { Phages According to } \\
\text { HHpred \# (Probability) }\end{array}$ & $\begin{array}{l}\text { BLASTp Viruses } \\
\text { (Identity) }\end{array}$ & $\begin{array}{l}\text { BLASTp Francisella } \\
\text { Group (Identity }{ }^{*} \text { ) }\end{array}$ \\
\hline Fhv_0041 (1024) & 085 & $\mathrm{HP}$ & $\begin{array}{l}\text { Regulatory protein cox } \\
\qquad(99 \%)\end{array}$ & - & $\begin{array}{l}\text { Francisella sp. SYW-9 } \\
\quad(64 \%) \\
\text { F. philomiragia }(48 \%)\end{array}$ \\
\hline Fhv_0042 (1025) & 212 & $\begin{array}{c}\text { Inhibitor_G39P } \\
\text { Blocking G40P replicative } \\
\text { helicase }\end{array}$ & Replisome organizer (100\%) & - & $\begin{array}{c}\text { Francisella sp. } \\
\text { FSC1006 (46\%) } \\
\text { F. philomiragia }(34 \%)\end{array}$ \\
\hline Fhv_0043 (1026) & 240 & $\begin{array}{l}\text { Phg_2220_C, (internal } \\
\text { repeat) } \\
\text { Phage replication protein }\end{array}$ & $\begin{array}{l}\text { DNA-binding protein TubR } \\
(97 \%)\end{array}$ & $\begin{array}{l}\text { Lactobacillus prophage Lj771 } \\
(50 \%)^{\circ}\end{array}$ & $\begin{array}{l}\text { Francisella sp. } \\
\text { FSC1006 (57\%) }\end{array}$ \\
\hline Fhv_0044 (1027) & 056 & $\begin{array}{c}\text { P22_Cro (lytic growth), } \\
\text { Cro protein, } \\
\text { phage_CI_repressor }\end{array}$ & Repressor protein $(98 \%)$ & $\begin{array}{c}\text { Erwinia phage vB_EhrS_59 } \\
(45 \%)\end{array}$ & $\begin{array}{l}\text { Francisella sp. } \\
\text { FSC1006 (45\%) }\end{array}$ \\
\hline Fhv_0045 (1028) & 265 & $\begin{array}{l}\text { Peptidase_S24_S26 SF, } \\
\text { CI-type HTH_XRE domain, } \\
\text { Pro-phage repressor (CI), } \\
\text { LexA protein domain, }\end{array}$ & Lambda Repressor (100\%) & $\begin{array}{c}\text { Streptococcus phage PH15 } \\
(48 \%)\end{array}$ & $\begin{array}{l}\text { F. philomiragia }(54 \%) \\
\text { F. salina }(52 \%) \\
\text { F. marina }(51 \%) \\
\text { F. novicida }(57 \%)\end{array}$ \\
\hline Fhv_0046 (1029) & 293 & $\mathrm{HP}$ & - & $\begin{array}{c}\text { Marinobacter phage AS1 } \\
(23 \%)\end{array}$ & - \\
\hline Fhv_0047 (1030) & 112 & HP, DUF4325 & - & $\begin{array}{c}\text { Campylobacter phage CP30A } \\
(27 \%)^{\circ}\end{array}$ & - \\
\hline Fhv_0048(n.a.) & 125 & $\mathrm{HP}, \mathrm{TM}$ & - & - & - \\
\hline Fhv_0049 (1031) & 264 & $\mathrm{HP}$ & - & - & $\begin{array}{l}\text { F. philomiragia }(45 \%) \\
\text { F. noatunensis }(45 \%)\end{array}$ \\
\hline Fhv_0050 (1032) & 130 & $\begin{array}{c}\text { TM, bPH_2 } \\
\text { Putative transmembrane } \\
\text { protein }\end{array}$ & Endolysin $(75 \%)^{\circ}$ & $\begin{array}{l}\text { Serratia phage phiMAM1 } \\
(39 \%)\end{array}$ & $\begin{array}{c}\text { Francisella sp. } \\
\text { W12-1067 (46\%) }\end{array}$ \\
\hline Fhv_0051 (1033) & 375 & $\begin{array}{c}\text { Phage_integrase, } \\
\text { Arm-DNA-bind_3 } \\
\text { Site-spezific } \\
\text { integrase/recombinase }\end{array}$ & Integrase $(100 \%)$ & $\begin{array}{l}\text { Prokaryotic dsDNA virus } \\
\text { sp. }(30 \%)\end{array}$ & $\begin{array}{c}\text { F. adeliensis }(62 \%) \\
\text { F. philomiragia }(56 \%) \\
\text { F. marina }(52 \%) \\
\text { F. salina }(51 \% \\
\text { )Francisella sp. SYW-9 } \\
(49 \%)\end{array}$ \\
\hline
\end{tabular}

* protein identity $>30 \%$; $* *$ ORF number (FN3523_00xx) in the genome of F. novicida-like strain 3523 (CP002558.1), now renamed to F. hispaniensis; \# https: / / toolkit.tuebingen.mpg.de (accessed on 12 February 2021) [38]; ${ }^{\circ}$ Myoviridae bacteriophage; LCR, low complexity region; DUF, domain of unknown function; HP, hypothetical protein; TM, transmembrane region; SF, super family; n.a., not annotated.

We performed BLASTp and HHpred analysis with all 51 ORFs and identified 44 ORFs showing similarities to known proteins of viruses of different bacteria (Escherichia, Erwinia, Halomonas, Pseudomonas, Ralstonia, Vibrio, Wolbachia, with identities ranging between 23$66 \%$ ) (Table 1; [38]). According to BLASTp results most of these viruses belong to the family of Myoviridae (represented by 20 homologues ORFs) and only few to the family of Siphoviridae (8 homologues ORFs; Table 1). 21 of these proteins revealed the highest concordance with proteins of Francisella sp. SYW-9 (GCF_008711465.1, draft genome) with identities of 30-64\% (Table 1). Two hypothetical proteins (Fhv_0032/49) and two integrases (Fhv_0033/51) exhibit homologs (29-62\% identity) to proteins in Fno, Fph and F. salina. The protein Fhv_0051 has been identified earlier to be the site-specific integrase of FhaGI-1, necessary for the integration and excision of the phage integration vector pFIV-Val and thus probably also for the prophage [19].

Phage proteins are generally less conserved and therefore often not recognizable by similarity in different virions, but some phage proteins are more conserved than others, and homology of these proteins can be recognized between phage types [20]. In the region of phage particle production (Figure 1B), we identified those ORFs which putatively encode the large (Fhv-0028) and small (Fhv-0031) subunit of the terminase, the portal protein (Fhv_0018), the tail tape measure protein (Fhv_0005), as well as the less conserved capsid protein (Fhv_0017), baseplate proteins (Fhv_0012/24/25), tail proteins (Fhv_0002/3/4/6/7/14/22/23) and tail sheath protein (Fhv_008). Proteins with 
regulatory/replication function (Fhv_0038/42-45, see above) and the site-specific integrase/recombinase (Fhv_0051) also seem to be less conserved (Table 1 and Figure 1).

We used 7 of the more "conserved" proteins (Fhv_0008, 12, 18, 23, 24, 25, 28) and the identified respective homologs of various bacteriophages (Table 1) to perform a phylogenetic tree analysis using these proteins as 7-loci concatenated protein sequences (Figure 3). The results demonstrated that the concatenated protein sequence of KIRK forms its own branch in a subclade together with the bacteriophages vB_EcoM-ECO-1230-10, vB_EcoMECO-ep3, Enterobacter Arya and Pseudomonas phiRSP, all belonging to the genus of Jilinvirus (Myoviridae). Based on the sequence analysis (BLASTp and phylogenetic tree), the identified prophage of Fhi 3523 might belong to the family of Myoviridae.

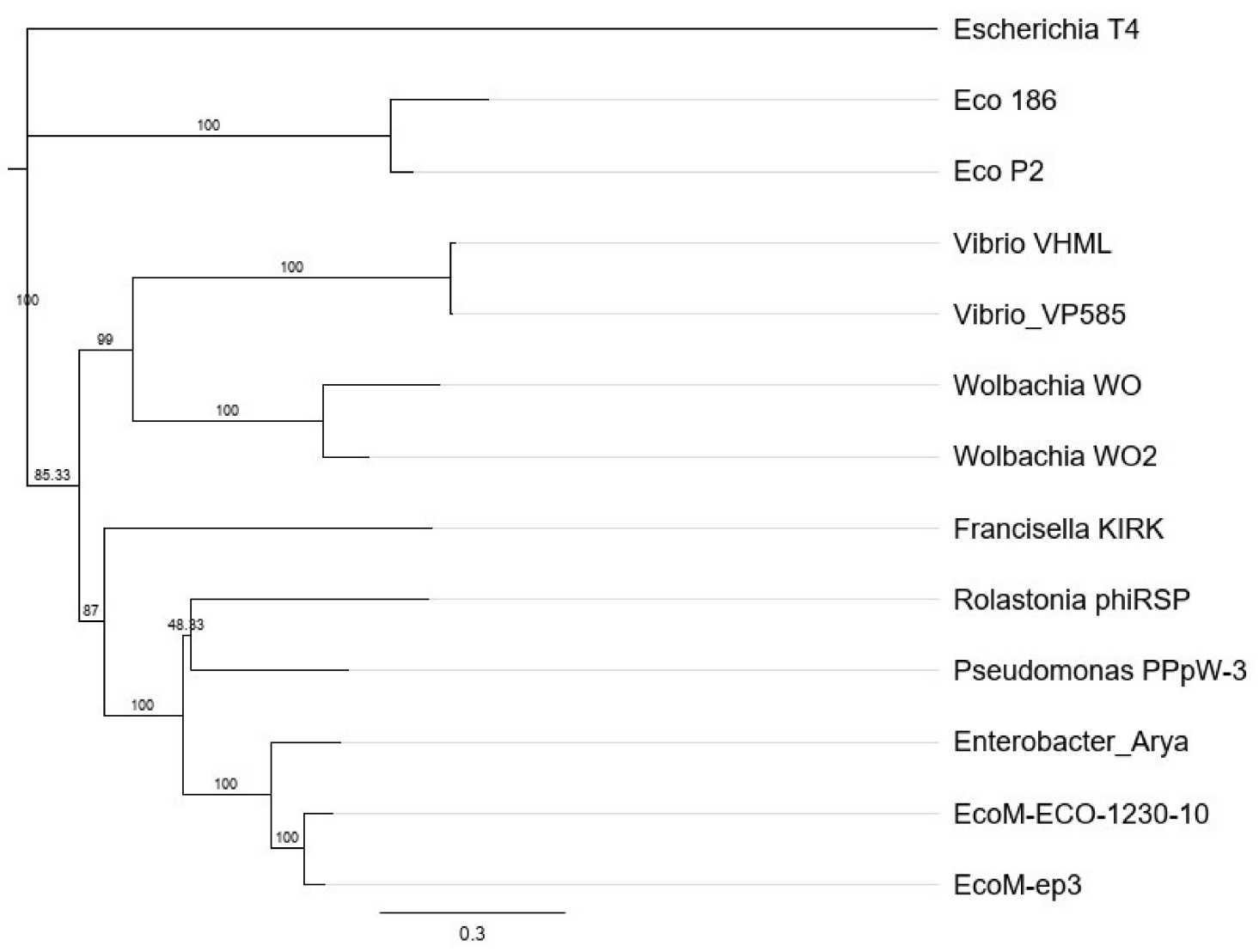

Figure 3. Phylogenetic tree analysis of the bacteriophage KIRK. 7 loci concatenated protein sequence of genes fhv_0018, 0024, 0012, 0008, 0025, 0028, 0023) and available homologous proteins from bacteriophages Escherichia T4 (Tevenvirinae, AF158101), Escherichia 186 (Peduovirinae, NC_001317), Escherichia P2 (Peduovirinae, KC618326), Vibrio VHML (Vhmlvirus, NC_004456), Vibrio VP585 (Vhmlvirus, NC_027981), Wolbachia WO2 (MK976036), Wolbachia WO (MN180249), Ralstonia phiRSP (Jilinvirus, MH252365), Pseudomonas PPpW3 (Jilinvirus, NC_023006), Enterobacter Arya (Jilinvirus, NC_031048), Escherichia ECO-1230-10 (Jilinvirus, GU903191) and Escherichia EcoM-ep3 (Jilinvirus, NC_025430) were used for amino acid sequences alignment using the ClustalO program in Geneious. The phylogenetic tree was generated by using Geneious Tree Builder, Neighbor-Joining method and Escherichia T4 phage as outgroup.

\subsection{Prophage Induction and Phage Characterization}

Since the putative prophage encodes a LexA motif containing repressor protein [18], we investigated if the prophage could be induced to be excised from the genome, to replicate and to propagate by lysing its host cell (Fhi 3523). To identify potential phage induction in a simplified way, a semi-quantitative PCR analysis amplifying the prophages' circular episomal form was established (Figure 4A). To achieve this, Fhi 3523 was cultivated in liquid medium $\mathrm{T}$ and pelleted. The supernatants were heat-treated, pelleted and analyzed by PCR analysis using the primer pair Fha2/Fha3 with 5, 10, 15 and 20 PCR 
amplification cycles. Primer Fha-2 and Fha-3 flank the attP site and therefore amplify the circular extrachromosomal form of the prophage but also the linear phage DNA might by amplified which is generated after prophage induction resulting in DNA replication by forming concatemers and production of virions. Phage DNA termini sites, like cos or pac sites depending on the packing mechanism and are usually located at different sites than the attP site. As shown in Figure 4A, after five PCR cycles no PCR product was observed, after 10 PCR cycles a weak band was obtained and after 15 and 20 PCR cycles, respectively, a distinct band appeared. Hence, we used the primer pair Fha2/Fha3 with 10 PCR amplification cycles to detect potential phage induction recognizable by increased band intensity compared with the non-induced control. We tested UV radiation, Mitomycin $\mathrm{C}$ treatment and growth at different temperatures as stress conditions for phage induction (Figure 4B-D). The experiments revealed that the prophage was inducible by UV radiation, since the excised episomal form of the prophage increased after UV radiation in a dosedependent manner (Figure 4B, 60 and 90 s). Treatment with either Mitomycin $C$ or growth temperatures above $37^{\circ} \mathrm{C}$ did not lead to an induction of the prophage (Figure 4C,D). However, a very small amount of the episomal form was detectable even without treatment $\left(0 \mathrm{~s}, 0 \mu \mathrm{g} / \mathrm{mL}, 37^{\circ} \mathrm{C}\right)$, but the amount did not change during the incubation time (Figure 4B-D, first row, 2-24 h). The yield of episomal form of the phage genome increased after UV radiation until about 4 to $6 \mathrm{~h}$ (Figure 4E, left), whereas the yield of chromosomal DNA (chromosomal gene Fn3523_1121) did not change considerably (Figure 4E, right). The increased yield of phage DNA was also detected in purified phage samples (DNase/RNase treated and sterile-filtered supernatants of UV-induced Fhi 3523 cultures; Figure 4F, upper row), which were devoid of bacterial DNA contamination (see Figure 4F, lower row). In these samples, only genes of the bacteriophage were amplified (Figure 4G, 1 to 4 ), but none of the chromosomal Fhi 3523 genes (Figure 4G, 5 and 6).

Furthermore, 5 to $6 \mathrm{~h}$ after prophage induction by UV radiation, negative staining electron microscopy (EM) of bacterial lysates (Figure 5A-C) and culture supernatants revealed the presence of bacteriophage particles. Phage particles composed of an icosahedral head of $52 \mathrm{~nm}(49-58 \mathrm{~nm})$ in diameter and a straight tail of $82 \mathrm{~nm}(71-97 \mathrm{~nm})$ in length and $9 \mathrm{~nm}(8-9.5 \mathrm{~nm})$ in width (Figure 5A-C). In addition, phage particles were detected also inside of the UV-induced bacterial cells (Fhi 3523) by thin section EM (Figure 5D,E), indicating phage replication, transcription and assembly within bacterial cells. Furthermore, EM images indicated that the head structures are filled with electron dense material which might correspond to DNA (Figure 5A-C). In combination with the fact that none of the chromosomal Fhi 3523 genes were amplified in purified phage samples, the results demonstrated that the head is filled with genomic DNA of the phage. Altogether the mentioned results and results of a phylogenetic tree analysis (see above, and Figure 3) indicated that the prophage, which is present in the genome of the Fhi 3523, encodes a temperate bacteriophage whose structure possesses similarities to members of Myoviridae or Siphoviridae. We named this bacteriophage "virus of Bacteria, identified in Francisella hispaniensis, with myovirus morphotype, named KIRK" (vB_FhiM_KIRK), following a recent informal guide (see discussion) [39].

Since we observed bacteriophage particles after UV radiation of Fhi 3523, we investigated if KIRK influences the growth behavior of treated bacterial cells in liquid medium $\mathrm{T}$ or inhibits the growth of other bacteria on agar plates (see Section 2.7). Here, a centrifugation step usually leading to samples with high phage titers was not practical since centrifugation of KIRK resulted in apparently defective phage particles, as observed by EM. Therefore, only the purified, but not concentrated supernatants of UV-induced Fhi 3523 cultures were used for liquid growth assays, spot tests and infection assays. Under the conditions tested here, lysis activity of phage KIRK was not observed, since purified phage samples did not decrease the growth of any Francisella or Legionella strain tested and further, no phage-mediated inhibition zones were observed on agar plates (tested strains: Fhi FSC454, Fth LVS, Fno U112 and Fx1, Fph ATCC 25015, F-W12, L. pneumophila strains Paris and Corby, L. micdadei, L. dumoffii, L. bozemanii, L. oakridgensis. Using F-W12 and Fth 
LVS strains in further infection experiments using KIRK or $\mathrm{KIRK}_{\text {rec, }}$ we yet could not show a successful infection of the bacteria by the bacteriophage particles.

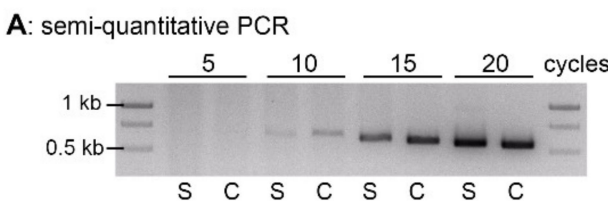

B: UV-radiation

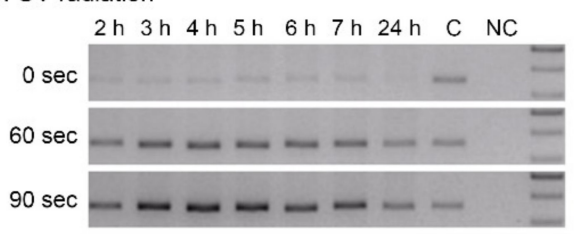

C: Mitomycin C

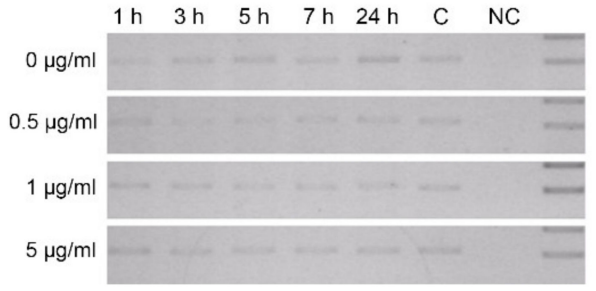

D: Temperature

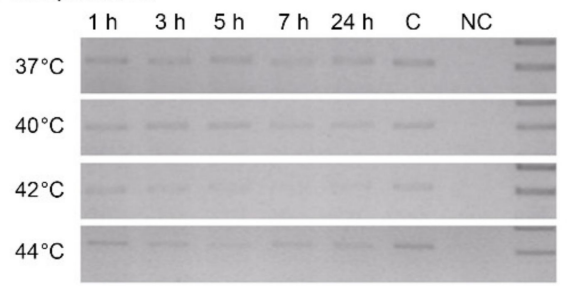

E: Phage induction

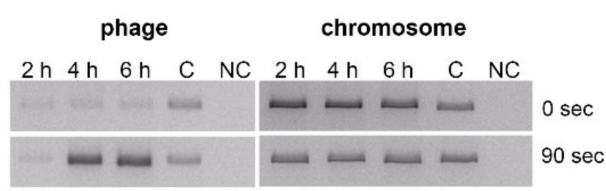

F: Phage DNA I

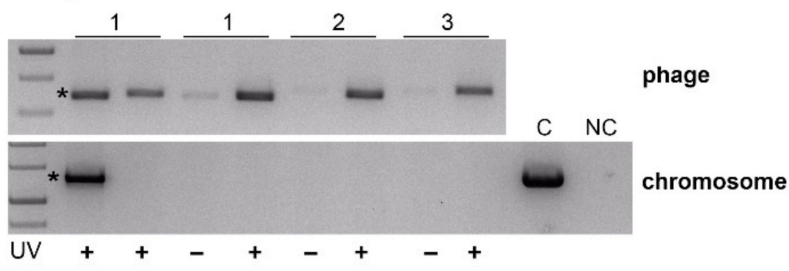

G: Phage DNA II

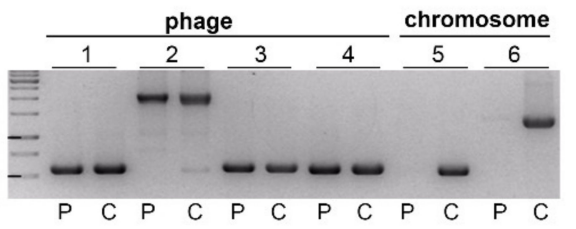

Figure 4. Bacteriophage induction. (A): Semi-quantitative PCR analyses. Supernatants of Fhi 3523 lysates (S) and control DNA of Fhi 3523 (C) were analyzed using primer Fha-2/Fha-3 (product size: 538 bp) with 5, 10, 15 and 20 PCR amplification cycles. (B-D): Fhi 3523 was exposed to UV radiation at $254 \mathrm{~nm}$ for 0,60 and $90 \mathrm{~s}$ (B); treated with $0,0.5,1$ and $5 \mu \mathrm{g} / \mathrm{mL}$ mitomycin C (C); or incubated at 37, 40, 42 and $44{ }^{\circ} \mathrm{C}$ (D). Samples were collected after various time points post-induction and used for PCR analyses with Fha-2/Fha-3 and 10 amplification PCR cycles. (E): PCR analyses were performed targeting the phage KIRK using primers Fha-2/Fha-3 (left, 538 bp) and bacterial genome of Fhi 3523 with primers Fhis_R13/Fhis_U13A (right, $1289 \mathrm{bp}$ ) after 0 and $90 \mathrm{~s}$ of $\mathrm{UV}$ radiation $(254 \mathrm{~nm})$ at different time points. (F): Supernatants $(1,2,3$, three replicates) of Fhi 3523 cultures treated with (+) or without (-) UV for $90 \mathrm{~s}$ at $254 \mathrm{~nm}$ were analyzed by PCR detecting the phage (Fha-2/Fha-3, 10 PCR cycles, upper row) and the bacterial Fhi 3523 chromosome (Fhis_U13A/Fhis_R13, lower row). All supernatants were treated with DNase and RNase and sterile filtered prior using in PCR analyses, except for sample marked by asterisk (control) which was not treated with DNase and RNase. (G): Purified, UV-induced phage samples (P) and control DNA of Fhi 3523 (C) were analyzed targeting FhaGI-1 (PCR 1-4) and chromosomal regions of Fhi 3523 (PCR 5, 6), respectively. 1: Fha-2/Fha-3 (538 bp); 2: Fha996_U/Fha997_R (2024 bp); 3: F1_out_U/F2_out_R (554 bp); 4 : F2_out_U/F3_out_R (530 bp); 5: Fha-1/Fha-4 (617 bp); 6: Fhis_R13/Fhis_U13A (1289 bp). C = control DNA of Fhi 3523 (whole DNA of bacterial cell lysates, see Section 2.2); NC = no template control; DNA ladder 1 kb GeneRuler was used. 

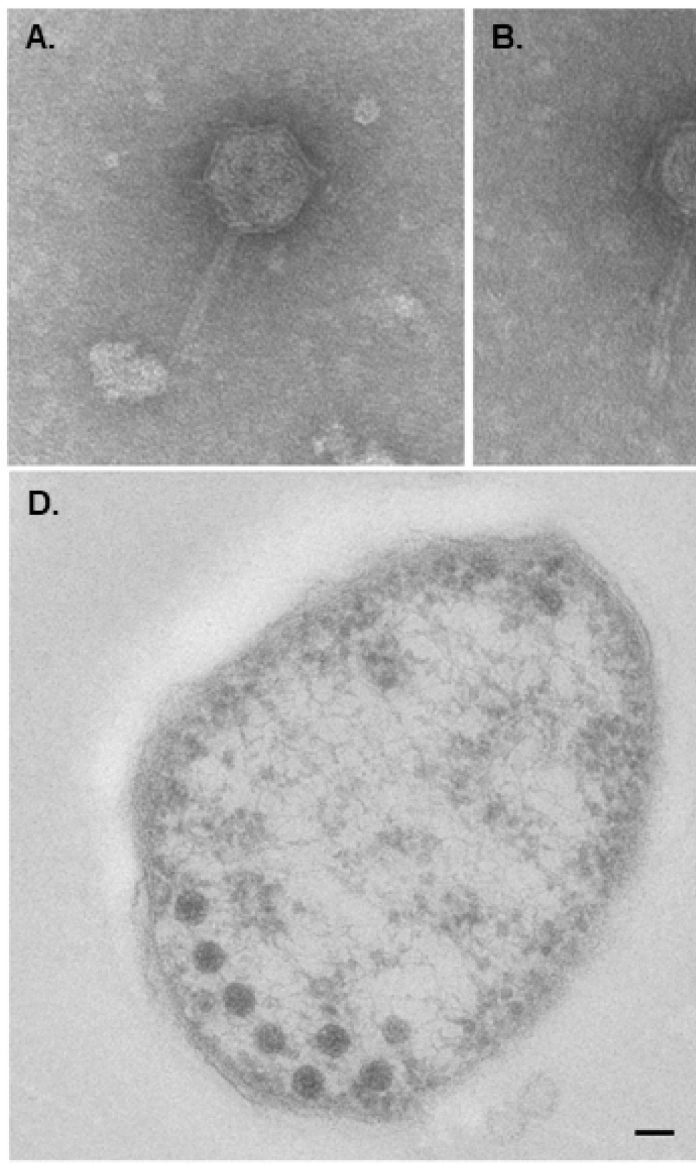
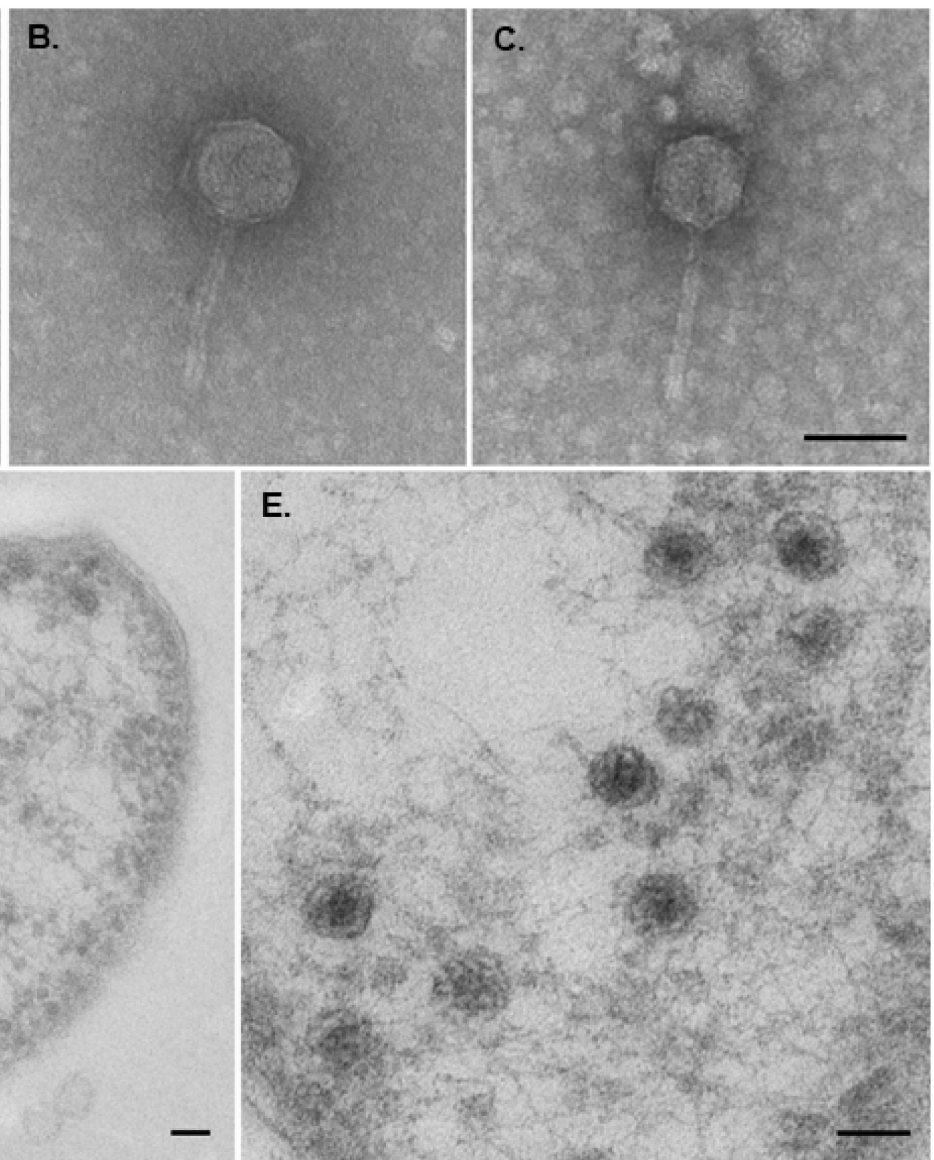

bar $=50 \mathrm{~nm}$

Figure 5. Electron micrographs of Francisella phage vB_FhiM_KIRK. (A-C): Transmission EM of purified KIRK samples (see Section 2.5) stained with uranyl acetate. Phage particles are composed of an icosahedral head $\sim 52 \mathrm{~nm}$ in diameter and a tail structure of $\sim 82 \mathrm{~nm}$ in length and $\sim 9 \mathrm{~nm}$ in width. (D,E): Thin section EM of UV treated Fhi 3523 cells, showing multiple phage particles inside of one bacterial cell. Bars $=50 \mathrm{~nm}$.

\subsection{The Recombinant KIRK (KIRK rec)}

Since the prophage containing strain was initially unavailable, we generated an in vitro synthesized recombinant form of KIRK, named $\mathrm{KIRK}_{\text {rec }}$ (see Supplemental Materials).

KIRK $_{\text {rec }}$ is tagged by a kanamycin resistance gene cassette which can be used experimentally as a selection marker in phage infection or transformation experiments. In a $\mathrm{KIRK}_{\text {rec }}$ positive $F$-W12 clone, $\mathrm{KIRK}_{\text {rec }}$ was successfully inducible by UV radiation and negative staining EM revealed the production of phage particles (Figure 6A). Complete icosahedral heads $(\sim 57 \mathrm{~nm}$ in diameter, $52-60 \mathrm{~nm})$ were visible, but a tail structure was not detected in the investigated samples (Figure 6A). The increased size of the head of KIRK rec may be a consequence of the increased size of the phage genome (additional kanamycin resitance and $g f p$ gene).

To further investigate if KIRK is infective for Francisella and/or is able to integrate into the genome of different Francisella strains (prophage state), we incubated Francisella strains with kanamycin-resistant $\mathrm{KIRK}_{\text {rec }}$ particles (purified UV-induced culture supernatants). However, when plated out on agar plates containing kanamycin we did not retrieve bacterial clones containing the recombinant bacteriophage $\mathrm{KIRK}_{\text {rec}}$. Then, the episomal form of $\mathrm{KIRK}_{\text {rec }}$ were extracted from UV-induced F-W12 $\mathrm{KIRK}_{\text {rec }}$ cultures (containing $\mathrm{KIRK}_{\text {rec }}$ as a prophage) and used for transformation into Francisella strains by electroporation. Here, we obtained Fth LVS and F-W12 clones harboring $\mathrm{KIRK}_{\text {rec, }}$ demonstrated by the presence of the episomal form of $\mathrm{KIRK}_{\text {rec }}$ as well as the site-specific chromosomal integration into 
tRNA-Val (Figure 6B). We did not obtain Fno (strains U112 and Fx1) and Fph (strain 25015) KIRK $_{\text {rec }}$ positive clones.

A.
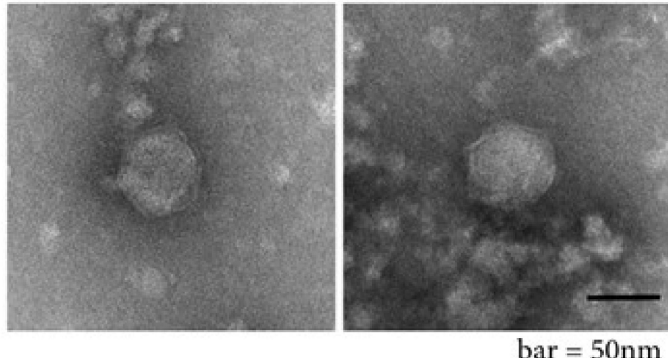

$\mathrm{bar}=50 \mathrm{~nm}$

B.

\section{circular form chromosomal integration}

\section{F-W12}

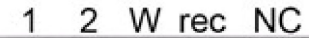
$12 \mathrm{~W}$ rec NC

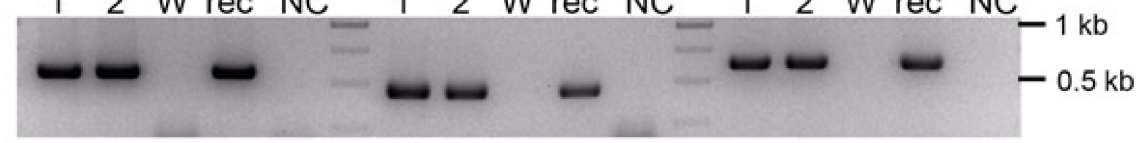

LVS

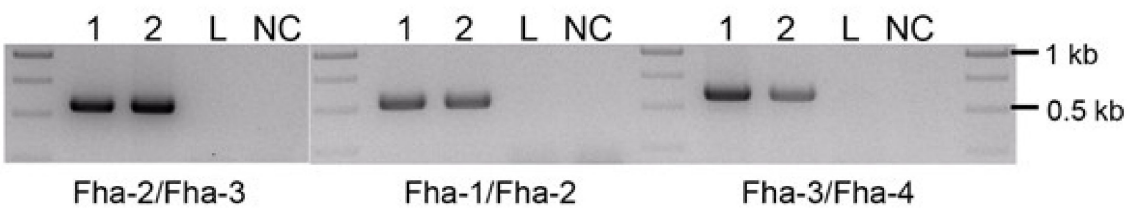

Figure 6. The recombinant bacteriophage $\mathrm{KIRK}_{\mathrm{rec}}$. (A): Transmission EM of purified $\mathrm{KIRK}_{\mathrm{rec}}$ stained with uranyl acetate. Phage particles are composed of an icosahedral head $\sim 57 \mathrm{~nm}$. (B): Infection of Francisella with $\mathrm{KIRK}_{\text {rec. }}$. Fth LVS and F-W12 were transformed with the episomal form of KIRK $\mathrm{rec}_{\text {by }}$ electroporation. Obtained clones were tested regarding the circular form of $\mathrm{KIRK}_{\text {rec }}$ using primer Fha-2/Fha-3 and the chromosomal integration using Fha-1/Fha-2 and Fha-3/Fha-4, here Fha-1 and Fha- 4 are species-specific primers binding in the genome of $F$-W12 (Fha- ${ }^{\mathrm{W} 12}$, Fha- $\mathrm{H}^{\mathrm{W} 12}$ ) and Fth LVS (Fha-1, Fha-4*), respectively, see Supplemental Table S1. 1, 2: F-W12 and Fth LVS KIKR rec clones, respectively; W: chromosomal DNA of F-W12, rec: F-W12 KIRK rec clone which was obtained by in vitro synthesis and cloning (see Supplemental Materials), and was used for extraction of circular form of $\mathrm{KIRK}_{\text {rec }}$ NC: no template control; L: chromosomal DNA of Fth LVS.

\section{Discussion}

The phage genome of KIRK is about 34,259 bp in length, it exhibits 51 ORFs and the GC content is $33.8 \%$, and thus slightly differs from that of the bacterial Fhi 3523 genome $(32.3 \%)$ [10]. As in other phages, the genome is organized in modular structures, with a main cluster of structural genes (Figure 1) or proteins involved in regulation/replication. In addition, analyzing ORF43, we identified a putative origin of replication which organization is comparable with that found in the Lambda phage [37,40]. A circular form of KIRK was assumed earlier [18]. In the Lambda phage, at first few circular forms of the phage genome are produced (bi-directional replication). In a second stage, long linear concatemers are synthesized by rolling circle replication and the concatemers are cut at the cos-sites (cohesive ends) into virus-sized length by the terminase. Cutting (terminase) and transport (portal protein) of the DNA into the head structure are done concomitantly [41]. Homologs of a terminase were found in the genome of KIRK and we confirmed the presence of a circular form of the phage. However, so far, we could not identify putative cos-sites of KIRK; also, other DNA replication and packaging strategies resulting in different types of DNA termini are plausible for KIRK, which needs to be investigated further.

In this work we demonstrated, that this prophage is inducible by UV radiation and bacteriophage particles were generated (see Figures 4 and 5). We called the phage 
vB_FhiM_KIRK, with KIRK as the common name. From the morphology of the observed phage particles, KIRK belongs to the order of Caudovirales (tailed phages with dsDNA), but EM analysis alone was not sufficient to classify KIRK as part of the Myoviridae or Siphoviridae. On the one hand a neck structure, separating tail and head, was not found and the observed tail structure seems to be too thin $(9 \mathrm{~nm}$, Figure 5) for phages belonging to Myoviridae, which usually possess neck and relatively thick double-sheathed tails (16-20 $\mathrm{nm})$. The analysis of the amino acid sequence of ORF Fhv_0008 revealed the presence of Pfam-Phage_sheath (1 and 1C) domain and BLASTp analysis did not reveal deletions within the sequence or evidence for a defective sheath protein. However, the tail width of about $9 \mathrm{~nm}$ found by EM fits to the size of the tail tube width of the Myoviridae which may be exposed by incomplete assembly of the tail or by a shedding of the tail tube/sheath protein [42]. This may also explain the inability of KIRK to re-infect bacteria (see below) and thus KIRK present in Fhi strain 3523 may represent a defective form of the bacteriophage. On the other hand, the obtained tail structure is short (71-97 nm), and the tails of Siphoviridae phages are rather long [41]. In addition, it is not clear if the tail of KIRK is either contractile and rigid, or non-contractile but flexible, which are also common features to discriminate between Myoviridae or Siphoviridae phages. However, of the proteins encoded by KIRK, 20 and 8 proteins exhibit similarity to Myoviridae and Siphoviridae, respectively, according to BLAST analysis. In addition, phylogenetic tree analysis of a 7 loci concatenated protein sequence (of the most conserved proteins) corroborated KIRK belonging to the family of Myoviridae, since the phylogenetic closest bacteriophages all belong to the genus Jilinvirus, belonging to the family of Myoviridae (see Figure 3).

The observed induction of the prophage by UV radiation is explainable by the presence of ORF45, encoding a putative homolog of the phage repressor CI exhibiting a LexA motif. In general, DNA damaged by UV radiation activates a host defense mechanism (SOS response) that helps the bacterium to survive, by degrading the bacterial LexA repressor, which represses a set of bacterial genes involved in DNA repair. However, this SOS system also leads to the degradation of CI, and thus to the induction of the prophage [43,44]. Our results indicated that this may also be true for the induction of KIRK. The PCR results (Figure 4, control, $(0 \mathrm{~s})$ ) indicated that a small amount of extrachromosomal KIRK is produced without induction which could be explained by the fact that temperate bacteriophages spontaneously and randomly are induced in a very small fraction of bacterial cells. Spontaneous lysis occurs once in about $10^{4}$ bacteria and is also RecA-dependent as a result of rare sporadic DNA damage [20]. Nevertheless, KIRK seems to be able to lyse its host (Fhi 3523) at least to a small extent since phage particles were observed in the supernatant of UVinduced Fhi 3523 cultures by electron microscopy and the yield of phage DNA increased in culture supernatants due to UV induction (Figure 4F). Basically, most phages with doublestranded nucleic acid genomes use lysozymes (endolysin) and holins for bacterial cell lysis. The lysis of the bacteria occurs at a strict defined time during the infective phage cycle [45]. So far, a holin protein has not been identified in silico in the genome of KIRK. Though, holins are a diverse group of enzymes with more than 250 proteins in more than 50 families, partially without significant sequence similarities making an in silico identification of such protein quite difficult [46]. ORF Fhv_0050 encodes a predictive endolysin according to HHpred analysis with 75\% probability to Enterobacteria phage T4 and Fhv_0025 of KIRK encodes a putative phage baseplate protein with lysozyme activity which exhibits $42 \%$ protein identity to the gp25-like lysozyme of Enterobacteria phage P88. This protein shows similarities to the T4 phage protein 25 which is a structural component of the baseplate and has also an acidic lysozyme activity [47]. Here, further investigations are needed including analysis of protein topology and function to identify proteins involved in lysis process. Moreover, other proteins are also involved in the phage-induced process of bacterial cell lysis like antiholins and spanins which have not been identified for KIRK yet [48].

For the survival of progeny virions, phages need to initiate infection including recognition and absorption to a suitable host, penetration of the cell wall and injection of phage DNA. The interaction between phages and host cells is primary driven by phage tail 
proteins and bacterial receptors. Therefore, intact tails are mandatory for successful infection and the following intracellular lifecycle including lysogenic and lytic pathway. So far, we were unable to show experimentally a KIRK infection of different Legionella and Francisella species. There are several explanations for this observation: (i) The tested conditions were insufficient and need to be optimized, especially the phage purification to reach high-concentrated phage samples. We used supernatants of UV-induced Fhi 3523 cultures for infection experiments since centrifugation of KIRK resulted in deformed phage particles observed by EM. (ii) KIRK might poorly attach, penetrate or inject its DNA into its host due to so far unknown reasons. (iii) The phage particles of KIRK released by UV-induced Fhi 3523 cells lack the tail sheath and thus are unable to re-infect new host bacteria; (iv) KIRK might be a "strong" temperate phage which predominately integrates into the genome rather than entering the lytic cycle. Nevertheless, DNA of KIRK ${ }_{\text {rec }}$ (episomal form) transformed into Francisella by electroporation integrated successfully into the

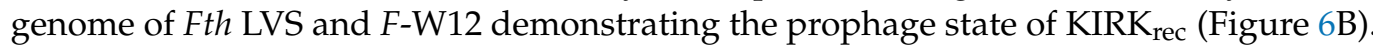
Moreover, the episomal form of the prophage was observed in Fth LVS and F-W12 after transformation. However, no Fno KIRK rec positive clone was obtained, suggesting that the active CRISPR-Cas system of Fno, containing KIRK-specific spacer DNAs, acts actively against the invading KIRK DNA [11,49].

Phages like the hereby described KIRK are likely vehicles for horizontal gene transfer and environmental phages are implicated in the network of genetic exchange among bacteria, which is also involved in the evolution of pathogens [50]. Recently, a putative Francisella conjugative element has been described but it is unknown if it is really involved in horizontal gene transfer [28]. However, since horizontal gene transfer in Francisella is not well understood, it is important to document and characterize putative gene transfer by temperate bacteriophages of Francisella. In addition, since phages are able to lyse bacteria, bacteriophages can be used also to specifically kill bacteria. Bacteriophage treatment is used as an alternative therapy for human infections, in food production and processing, as well as for microbial decontamination [51-53]. Although our phage is lysogenic and lytic capacity is not well understood, it possesses the potential usage in the abatement of Francisella sp. e.g., by genetically enhancing the lytic capacity and elimination of the lysogenic modus of the phage. Such a modified bacteriophage KIRK might be helpful to decontaminate environmental areas exhibiting high concentrations of the highly pathogenic species F. tularensis.

In summary, KIRK seems to be a temperate bacteriophage present in the environment, and the prophage KIRK present in strain Fhi 3523 seems to represent a defective form of this bacteriophage, demonstrated by following observations: (i) the identification of the complete genome of the prophage in a Francisella strain (Fhi 3523), indicating that Fhi 3523 has been infected successfully by KIRK in its natural habitat, (ii) the identification of various different anti-KIRK spacer sequences in the CRISPR region of different Fno strains [11], indicating a direct contact of these strains with the bacteriophage KIRK in the environment, (iii) the demonstration of phage assembly and multiplication within bacterial cells (Figure $5 \mathrm{D}, \mathrm{E}$ ) and (iv) the detection of phage particles in bacterial culture supernatants indicating lytic capacity. Furthermore, KIRK may be ubiquitous in natural (aquatic) habitats, since KIRK or KIRK-specific DNA spacers (CRISPR) were found in strains isolated in Australia ( $F h i$ 3523, from a patient infected by brackish water) and in different parts of the USA (Fno U112, Utah, aquatic environmental isolate; Fno GA99-3548, Louisiana; GA99-3549, California, Fno Fx1, Texas, patient isolate). The prophage present in strain Fhi 3523 may be unable to re-infect new bacteria because of a defective tail sheath structure.

Supplementary Materials: The following are available online at https:/ / www.mdpi.com/1999-491 5/13/2/327/s1, Figure S1: Cloning strategy of the recombinant bacteriophage KIRKrec. Table S1: Primers used in this study. 
Author Contributions: Conceptualization, K.H.; methodology, validation, investigation and formal analysis, K.K., G.I.P., K.R., H.T., G.H., K.H.; writing-original draft preparation and editing, K.H., G.H., K.K.; supervision, K.H. All authors have read and agreed to the published version of the manuscript.

Funding: This research received no external funding.

Acknowledgments: We thank Jeannine Petersen, John Young and Laurel Respicio-Kingry (Centers for Disease Control and Prevention, Fort Collins, CO 80521, USA) for providing F. hispaniensis strain 3523. We also thank Roland Grunow for reading the references written in Russian. This work received financial support from the Robert Koch Institute. No financial conflicts of interest regarding the contents of the manuscript and its authors exist.

Conflicts of Interest: The authors declare no conflict of interest.

\section{References}

1. Ellis, J.; Oyston, P.C.; Green, M.; Titball, R.W. Tularemia. Clin. Microbiol. Rev. 2002, 15, 631-646. [CrossRef] [PubMed]

2. Sjostedt, A. Special Topic on Francisella tularensis and Tularemia. Front. Microbiol. 2011, 2, 86. [CrossRef] [PubMed]

3. Keim, P.; Johansson, A.; Wagner, D.M. Molecular epidemiology, evolution, and ecology of Francisella. Ann. N. Y. Acad. Sci. 2007, 1105, 30-66. [CrossRef] [PubMed]

4. Clarridge, J.E., 3rd; Raich, T.J.; Sjosted, A.; Sandstrom, G.; Darouiche, R.O.; Shawar, R.M.; Georghiou, P.R.; Osting, C.; Vo, L. Characterization of two unusual clinically significant Francisella strains. J. Clin. Microbiol. 1996, 34, 1995-2000. [CrossRef] [PubMed]

5. Hollis, D.G.; Weaver, R.E.; Steigerwalt, A.G.; Wenger, J.D.; Moss, C.W.; Brenner, D.J. Francisella philomiragia comb. nov. (formerly Yersinia philomiragia) and Francisella tularensis biogroup novicida (formerly Francisella novicida) associated with human disease. J. Clin. Microbiol. 1989, 27, 1601-1608. [CrossRef]

6. Whipp, M.J.; Davis, J.M.; Lum, G.; de Boer, J.; Zhou, Y.; Bearden, S.W.; Petersen, J.M.; Chu, M.C.; Hogg, G. Characterization of a novicida-like subspecies of Francisella tularensis isolated in Australia. J. Med. Microbiol. 2003, 52, 839-842. [CrossRef]

7. Sjodin, A.; Svensson, K.; Ohrman, C.; Ahlinder, J.; Lindgren, P.; Duodo, S.; Hnath, J.; Burans, J.P.; Johansson, A.; Colquhoun, D.J.; et al. Genome characterisation of the genus Francisella reveals insight into similar evolutionary paths in pathogens of mammals and fish. BMC Genom. 2012, 13, 268. [CrossRef]

8. $\quad$ Escudero, R.; Elia, M.; Saez-Nieto, J.A.; Menendez, V.; Toledo, A.; Royo, G.; Rodriguez-Vargas, M.; Whipp, M.J.; Gil, H.; Jado, I.; et al. A possible novel Francisella genomic species isolated from blood and urine of a patient with severe illness. Clin. Microbiol. Infect. 2010, 16, 1026-1030. [CrossRef]

9. Huber, B.; Escudero, R.; Busse, H.J.; Seibold, E.; Scholz, H.C.; Anda, P.; Kampfer, P.; Splettstoesser, W.D. Description of Francisella hispaniensis sp. nov., isolated from human blood, reclassification of Francisella novicida (Larson et al. 1955) Olsufiev et al. 1959 as Francisella tularensis subsp. novicida comb. nov. and emended description of the genus Francisella. Int. J. Syst. Evol. Microbiol. 2010, 60, 1887-1896. [CrossRef]

10. Siddaramappa, S.; Challacombe, J.F.; Petersen, J.M.; Pillai, S.; Hogg, G.; Kuske, C.R. Common ancestry and novel genetic traits of Francisella novicida-like isolates from North America and Australia as revealed by comparative genomic analyses. Appl. Environ. Microbiol. 2011, 77, 5110-5122. [CrossRef]

11. Schunder, E.; Rydzewski, K.; Grunow, R.; Heuner, K. First indication for a functional CRISPR/Cas system in Francisella tularensis. Int. J. Med. Microbiol. 2013, 303, 51-60. [CrossRef] [PubMed]

12. Barrangou, R.; Fremaux, C.; Deveau, H.; Richards, M.; Boyaval, P.; Moineau, S.; Romero, D.A.; Horvath, P. CRISPR provides acquired resistance against viruses in prokaryotes. Science 2007, 315, 1709-1712. [CrossRef] [PubMed]

13. Deveau, H.; Garneau, J.E.; Moineau, S. CRISPR/Cas system and its role in phage-bacteria interactions. Annu. Rev. Microbiol. 2010, 64, 475-493. [CrossRef] [PubMed]

14. Horvath, P.; Barrangou, R. CRISPR/Cas, the immune system of bacteria and archaea. Science 2010, 327, 167-170. [CrossRef] [PubMed]

15. Kunin, V.; Sorek, R.; Hugenholtz, P. Evolutionary conservation of sequence and secondary structures in CRISPR repeats. Genome Biol. 2007, 8, R61. [CrossRef] [PubMed]

16. Makarova, K.S.; Aravind, L.; Wolf, Y.I.; Koonin, E.V. Unification of Cas protein families and a simple scenario for the origin and evolution of CRISPR-Cas systems. Biol. Direct. 2011, 6, 38. [CrossRef] [PubMed]

17. Makarova, K.S.; Haft, D.H.; Barrangou, R.; Brouns, S.J.; Charpentier, E.; Horvath, P.; Moineau, S.; Mojica, F.J.; Wolf, Y.I.; Yakunin, A.F.; et al. Evolution and classification of the CRISPR-Cas systems. Nat. Rev. Microbiol. 2011, 9, 467-477. [CrossRef]

18. Rydzewski, K.; Tlapak, H.; Niehaus, I.P.; Dabrowski, P.W.; Grunow, R.; Heuner, K. Identification and characterization of episomal forms of integrative genomic islands in the genus Francisella. Int. J. Med. Microbiol. 2015, 305, 874-880. [CrossRef] [PubMed]

19. Tlapak, H.; Koppen, K.; Rydzewski, K.; Grunow, R.; Heuner, K. Construction of a New Phage Integration Vector pFIV-Val for Use in Different Francisella Species. Front. Cell. Infect. Microbiol. 2018, 8, 75. [CrossRef] 
20. Casjens, S. Prophages and bacterial genomics: What have we learned so far? Mol. Microbiol. 2003, 49, 277-300. [CrossRef] [PubMed]

21. Ohnishi, M.; Kurokawa, K.; Hayashi, T. Diversification of Escherichia coli genomes: Are bacteriophages the major contributors? Trends Microbiol. 2001, 9, 481-485. [CrossRef]

22. Banks, D.J.; Beres, S.B.; Musser, J.M. The fundamental contribution of phages to GAS evolution, genome diversification and strain emergence. Trends Microbiol. 2002, 10, 515-521. [CrossRef]

23. Koliaditskaia, L.S.; Kuchina, K.V.; Shmurygina, A.A. [Tularemia bacteriophage; preliminary communication]. Zh. Mikrobiol. Epidemiol. Immunobiol. 1959, 30, 13-17. [PubMed]

24. Lammertyn, E.; Vande Voorde, J.; Meyen, E.; Maes, L.; Mast, J.; Anne, J. Evidence for the presence of Legionella bacteriophages in environmental water samples. Microb. Ecol. 2008, 56, 191-197. [CrossRef]

25. Grigor'ev, A.A.; Bondarev, V.P.; Borisevich, I.V.; Darmov, I.V.; Mironin, A.V.; Zolotarev, A.G.; Pogorel'skii, I.P.; Ianov, D.S. [Temperate Legionella bacteriophage: Discovery and characteristics]. Zh. Mikrobiol. Epidemiol. Immunobiol. 2008, 86-88.

26. Alharby, A.M. Isolation and charakterization of a novel bacteriophage, ASC10, that lyses Francisella tularensis. Ph.D. Theses, Colorado State University, Fort Collins, CO, USA, 2014.

27. Sampson, T.R.; Weiss, D.S. Cas9-dependent endogenous gene regulation is required for bacterial virulence. Biochem. Soc. Trans. 2013, 41, 1407-1411. [CrossRef] [PubMed]

28. Siddaramappa, S.; Challacombe, J.F.; Petersen, J.M.; Pillai, S.; Kuske, C.R. Comparative analyses of a putative Francisella conjugative element. Genome 2014, 57, 137-144. [CrossRef] [PubMed]

29. Sridhar, S.; Sharma, A.; Kongshaug, H.; Nilsen, F.; Jonassen, I. Whole genome sequencing of the fish pathogen Francisella noatunensis subsp. orientalis Toba04 gives novel insights into Francisella evolution and pathogenecity. BMC Genom. 2012 , 13, 598. [CrossRef]

30. Rydzewski, K.; Schulz, T.; Brzuszkiewicz, E.; Holland, G.; Luck, C.; Fleischer, J.; Grunow, R.; Heuner, K. Genome sequence and phenotypic analysis of a first German Francisella sp. isolate (W12-1067) not belonging to the species Francisella tularensis. BMC Microbiol. 2014, 14, 169. [CrossRef] [PubMed]

31. Jepras, R.I.; Fitzgeorge, R.B.; Baskerville, A. A comparison of virulence of two strains of Legionella pneumophila based on experimental aerosol infection of guinea-pigs. Epidemiol. Infect. 1985, 95, 29-38. [CrossRef]

32. Becker, S.; Lochau, P.; Jacob, D.; Heuner, K.; Grunow, R. Successful re-evaluation of broth medium T for the growth of Francisella tularensis ssp. and other higly pathogenic bacteria. J. Microbiol. Methods 2016, 121, 5-7. [CrossRef]

33. Pavlovich, N.V.; Mishan'kin, B.N. [Transparent nutrient medium for culturing Francisella tularensis]. Antibiot. Med. Biotekhnol. 1987, 32, 133-137.

34. Edelstein, P.H. Improved semiselective medium for isolation of Legionella pneumophila from contaminated clinical and environmental specimens. J. Clin. Microbiol. 1981, 14, 298-303. [CrossRef] [PubMed]

35. Woods, W.H.; Egan, J.B. Prophage induction of noninducible coliphage 186. J. Virol. 1974, 14, 1349-1356. [CrossRef] [PubMed]

36. Hockett, K.L.; Baltrus, D.A. Use of the Soft-agar Overlay Technique to Screen for Bacterially Produced Inhibitory Compounds. J. Vis. Exp. 2017. [CrossRef]

37. Schnos, M.; Zahn, K.; Inman, R.B.; Blattner, F.R. Initiation protein induced helix destabilization at the lambda origin: A prepriming step in DNA replication. Cell 1988, 52, 385-395. [CrossRef]

38. Zimmermann, L.; Stephens, A.; Nam, S.Z.; Rau, D.; Kubler, J.; Lozajic, M.; Gabler, F.; Soding, J.; Lupas, A.N.; Alva, V. A Completely Reimplemented MPI Bioinformatics Toolkit with a New HHpred Server at its Core. J. Mol. Biol. 2018, 430, 2237-2243. [CrossRef]

39. Adriaenssens, E.; Brister, J.R. How to Name and Classify Your Phage: An Informal Guide. Viruses 2017, 9. [CrossRef] [PubMed]

40. Weigel, C.; Seitz, H. Bacteriophage replication modules. FEMS Microbiol. Rev. 2006, 30, 321-381. [CrossRef] [PubMed]

41. Ackermann, H.W. Bacteriophage observations and evolution. Res. Microbiol. 2003, 154, 245-251. [CrossRef]

42. Kostyuchenko, V.A.; Chipman, P.R.; Leiman, P.G.; Arisaka, F.; Mesyanzhinov, V.V.; Rossmann, M.G. The tail structure of bacteriophage T4 and its mechanism of contraction. Nat. Struct. Mol. Biol. 2005, 12, 810-813. [CrossRef]

43. Maslowska, K.H.; Makiela-Dzbenska, K.; Fijalkowska, I.J. The SOS system: A complex and tightly regulated response to DNA damage. Environ. Mol. Mutagen. 2019, 60, 368-384. [CrossRef]

44. Hochschild, A.; Lewis, M. The bacteriophage lambda CI protein finds an asymmetric solution. Curr. Opin. Struct. Biol. 2009, 19, 79-86. [CrossRef]

45. Wang, I.N.; Smith, D.L.; Young, R. Holins: The protein clocks of bacteriophage infections. Annu. Rev. Microbiol. 2000, 54, 799-825. [CrossRef] [PubMed]

46. Reddy, B.L.; Saier, M.H., Jr. Topological and phylogenetic analyses of bacterial holin families and superfamilies. Biochim. Biophys. Acta 2013, 1828, 2654-2671. [CrossRef]

47. Szewczyk, B.; Bienkowska-Szewczyk, K.; Kozloff, L.M. Identification of T4 gene 25 product, a component of the tail baseplate, as a 15K lysozyme. Mol. Gen. Genet. 1986, 202, 363-367. [CrossRef]

48. Cahill, J.; Young, R. Phage Lysis: Multiple Genes for Multiple Barriers. Adv. Virus Res. 2019, 103, 33-70. [CrossRef] [PubMed]

49. Ratner, H.K.; Weiss, D.S. Francisella novicida CRISPR-Cas Systems Can Functionally Complement Each Other in DNA Defense while Providing Target Flexibility. J. Bacteriol. 2020, 202. [CrossRef]

50. Chen, J.; Novick, R.P. Phage-mediated intergeneric transfer of toxin genes. Science 2009, 323, 139-141. [CrossRef] [PubMed] 
51. Kakasis, A.; Panitsa, G. Bacteriophage therapy as an alternative treatment for human infections. A comprehensive review. Int. J. Antimicrob. Agents 2019, 53, 16-21. [CrossRef]

52. Moye, Z.D.; Woolston, J.; Sulakvelidze, A. Bacteriophage Applications for Food Production and Processing. Viruses 2018, 10, 205. [CrossRef] [PubMed]

53. Courchesne, N.M.; Parisien, A.; Lan, C.Q. Production and application of bacteriophage and bacteriophage-encoded lysins. Recent Pat. Biotechnol. 2009, 3, 37-45. [CrossRef] [PubMed] 